\title{
A Study on Offshore Wind Farm Siting Criteria Using a Novel Interval-valued Fuzzy-rough based Delphi Method
}

\begin{abstract}
This study investigates the degree of importance of criteria affecting the optimal site selection of offshore wind farms. Firstly, forty two different influential criteria have been selected by reviewing the scientific literature on offshore wind farm site selection. Secondly, a survey has been conducted receiving a response from thirty four internationally renowned experts across seventeen countries. Each participant is asked to indicate the importance and relevance of each criterion based on their experience. Finally, the importance of each criterion for offshore wind farm site selection is determined using a novel Decision MakingLevel Based Weight Assessment (LBWA) approach based on interval-valued fuzzy-rough numbers (IVFRN). The proposed method allows exploitation of the uncertainties and subjectivity that exist in the decision-making process. The results from this study improve our understanding of the importance and impact of each criterion which we believe would be invaluable for the future studies on the site selection of offshore wind farms.

Keywords: Renewable energy, offshore wind farm, site selection, criteria, Delphi technique, interval-valued fuzzy-rough numbers, traditional type-1 fuzzy numbers.
\end{abstract}

\section{Introduction}

Renewable energy is clean and cheap, collected from renewable resources, such as, hydro-power, biomass, geothermal, solar, wind and so on Breton and Moe, 2009). Wind energy, in particular, has been constantly growing and devel-

Preprint submitted to Journal of Environmental Management

June 30, 2020 
oping in the recent years (Mostafaeipour, 2010). It introduces more advantages in terms of cost, sustainability, and competition when compared to the other renewable energy sources (Kempton et al. 2005).

After the Kyoto conference at the end of 1997, especially on the global climate change, the offshore wind energy has become the focal point of national and international organizations after the restriction of fossil fuel consumption, adopted by many developed countries (Gaudiosi, 1999). In recent years, the wind energy industry has started to move towards the offshore market, and thousands of megawatt (MW) - capacity wind farms have been installed offshore, because of large-scale electricity generation (Markard and Petersen, 2009). Offshore wind energy has become an increasingly attractive option owing to its large offshore areas and enormous energy potential (Breton and Moe, 2009).

The offshore wind farms (OWFs) have less turbulence than the onshore winds, leading to much higher speeds. Higher speed means generation of more electricity. If the speed of wind produced, increases proportionally to the cube, going to the marine areas for a few kilometres from the land provides a significant increase in electricity generation. For example, it is possible to produce $60 \%$ more electricity from a wind turbine with an average wind speed of $28 \mathrm{~km} / \mathrm{h}$ compared to one with an average wind speed of $22 \mathrm{~km} / \mathrm{h}$. This wind power shows how vital the speed factor is in electricity generation (Kurian et al. 2010.

Northern Europe is the region where the offshore wind energy was introduced for the first time owing to the intensive use of limited available land areas and high wind capacity (Gaudiosi, 1999). European offshore wind farms are concentrated in the North Sea and the Baltic Sea (Denmark, Sweden, Germany and the Netherlands). The characteristics of the northern seas, such as the continuity of depth, and high sea wind not exceeding $60 \mathrm{~m}$, allows for offshore wind farms. The wide area at low depth allows the turbines to be installed directly on the seabed with monopiles or jackets, and convenient winds provide simple wind energy potential (Del Jesus et al., 2014).

Although offshore wind farms are based on a 'clean' technology, they may have some negative effects on the marine life, sport fishery, navigational risks, 
impact of radio and radar corridors, tourist, environmental impact, or local residents. While the positioning of wind turbines in the offshore eliminates noise disturbance, it may cause aesthetic externalities and especially visual impact (Ladenburg and Dubgaard, 2007). Energy companies or governments must consider the conflicts between these OWF siting interests (Ho et al., 2018). Site selection is the key to the success of OWF projects both economically, technically, environmentally and socially (Cali et al. 2018).

Today, many countries in the world are facing increasing restrictions on the evaluation of optimal sites for offshore wind development. The criteria that affect the investment and acceptance of OWF site selection have become increasingly important by energy companies (Ho et al., 2018). Research on OWF site selection has improved our understanding of the criteria that affect the future of OWF. So far, many criteria have been defined for site selection; weather conditions, operation/profitability, environmental impact, social (Community/local acceptance), power networks (grid connections), shipping density, incentives, characteristics of the region and so on. These criteria are examined in detail in Section 2.3 .

In practice, the priority and ranking of each criterion in OWF site selection is of considerable importance. The Delphi method, which is an expert group decision-making technique, can be used to determine the importance level and ranking of criteria. However, due to lack of information, time pressure, decisionmakers may not be able to provide a (top-down) ranking of criteria. Instead, some criteria can be ranked equally well or only to some degree better than other criteria. In such cases, it might be more useful to utilise fuzzy-sets-based ranking approach instead of the crisp rankings.

The interval-valued fuzzy-rough number (IVFRN) approach presented in this paper involves defining the initial reference fuzzy set, by means of which the uncertainty in Delphi is described. After defining the initial fuzzy set, the uncertainties contained in the evaluations of the decision makers (DM) are measured by means of rough sets. This leads to the objective indicators contained in the data. Interval-valued fuzzy-rough numbers take advantage of both the 
theory of fuzzy sets and rough numbers (Pamučar et al. 2018, 2019). At the same time, using the advantages of both approaches (fuzzy and rough) IVFRN eliminate the disadvantages of fuzzy sets type-1 and interval-valued fuzzy sets (Roy et al., 2019). The advantages of implementing IVFRN in the Delphi are numerous. IVFRN use only internal knowledge to present the limit values of the attributes of a decision. In this way, subjectivity and assumptions when defining the limit values of traditional fuzzy sets are eliminated that could affect the values of the attribute and the final choice of alternatives. When using IVFRN, instead of using additional/external parameters, the structure of the given data is exclusively used. In this way, uncertainties that already exist in the data are used, improving the objectivity of the decision process (Pamučar et al. 2018). Another advantage of this approach is the suitability of IVFRN for use in sets characterized by a small amount of data, and for which traditional statistical models are not suitable.

This study presents a novel variant of the LBWA (Level Based Weight Assessment) model (Žižović and Pamucar, 2019) with the goal of determining the weight coefficients of OWF criteria in interval-valued fuzzy-rough environment. The LBWA model is novel technique for determining weight coefficients of criteria in multi-criteria decision-making models. The model enables the involvement of experts from different fields with the purpose of defining the relations between criteria and providing rational decision making. It can be applied in wide range of practical cases in specialized decision-making support systems, as well as in alternative dispute resolutions in virtual environment. The LBWA model has several key advantages over the other subjective models based on mutual comparison of criteria as listed below: (i) the LBWA model allows the calculation of weight coefficients with less number of criteria comparisons, i.e., only $n-1$ comparisons, where $n$ is the number of criteria; (ii) the algorithm of the LBWA can scale as the number of criteria increases, which makes it suitable even for the complex multi-criteria (MCDM) models with a large number of criteria; (iii) by applying the LBWA model, optimal values of weight coefficients are obtained with simple mathematical apparatus that eliminates inconsistencies in 
expert preferences, which are tolerated in certain subjective models (Best Worst Method - BWM and Analytic Hierarchy Process - AHP); (iv) the elasticity coefficient of the LBWA model enables, after comparing the criteria, additional corrections of the values of the weight coefficients depending on the preferences of the decision makers.

The aim of this study is to rank offshore wind farm site selection criteria using Delphi method based on interval-valued fuzzy-rough numbers. We have conducted an online survey to identify the importance of 42 criteria for the site selection of OWF. 34 international experts from 16 countries with a wide range of expertise and disciplines, who adequately represented the subject area, filled out the questionnaire. Due to the long list of possible criteria, some of them requiring prior knowledge in the domain we had to limit our target population to experts in the field. We provide our findings in this study, which we believe to have important implications for future research and practice. The main contributions of this paper are as follows: (i) identify the importance of various criteria for the site selection of offshore wind farms (ii) the design of a novel Delphi- Level Based Weight Assessment approach based on intervalvalued fuzzy-rough numbers for various ranking problems (iii) the development of an integrated model for determining the weight coefficients of criteria and evaluation.

The remainder of this paper is structured as follows: Section 2 presents an overview of fuzzy ranking techniques. The offshore wind farm siting criteria are defined in Section 2.3 Section 3 introduces the interval-valued fuzzy-rough numbers and extended Delphi method. A questionnaire to identify the importance of various criteria are conducted in Section 4. Section 5 is given the survey results, and the results and discussion are presented in Section 6. Finally, section 7 includes the conclusions of this study. 


\section{Background}

\subsection{Related Work on Offshore Wind Farm Site Selection}

Many studies have been published about OWF site selection in the literature using various siting criteria. Vagiona and Karanikolas (2012) assessed offshore wind farm sites using multi-criteria approach considering five evaluation criteria such as wind velocity, protected areas, ship routes, distance from to shore and electricity network. Fetanat and Khorasaninejad (2015) proposed multi-criteria decision making method to find the best site selection of OWF. They considered six criteria that include depths and heights, proximity to facilities, resource technical levels and culture, environmental and economic issues, and sub-criteria to select suitable sites for OWF. Wu et al. (2016) structured a framework for OWF site selection based on 6 main and 22 sub-criteria. Chaouachi, Covrig and Ardelean (2017) presented a multi-criteria selection of offshore wind farm sites taking into consideration three main and six sub-criteria. Argin et al. (2019) investigated the offshore wind energy potential of Turkey based on multi-criteria site selection. They used eight site selection criteria their studies.

There has been many techniques concerning criteria or alternative ranking in the literature such as multi-criteria decision making methods that include TOPSIS (Technique for Order Performance by Similarity to Ideal Solution, VIKOR (VIseKriterijumska Optimizacija I Kompromisno Resenje, ELECTRE (ELimination Et Choix Traduisant la REalitwas), Choquet integral, AHP/ANP (Analytic Hierarchy/Network Process), and so on. One of them is delphi technique that can be used for determining the importance of criteria and screening key criteria (Nordman et al., 2013).

\subsection{Delphi Method and IVFRN Numbers}

The Delphi Method was first introduced by Dalkey and Helmer (1963) which is a group knowledge acquisition approach (Habibi et al., 2015). The main aim of the this method is to extract the common opinion of a group of selected experts, arriving at a consensus in a sense. Another technique used in recent 
years is fuzzy Delphi method. This method was derived from the classical Delphi method and fuzzy sets (Ishikawa et al., 1993). Various studies have been done by using fuzzy Delphi techniques such as, human resources (Chang et al. 2000), evaluating hydrogen production technologies (Chang et al., 2011), Ranking the sawability of ornamental stone (Mikaeil et al., 2013), forecasting and screening items (Habibi et al., 2015), evaluation of sustainable eco-tourism indicators Ocampo et al. (2018), choosing the locations of logistics centers (Pham et al. 2017), assessment of consumers' motivations (Vafadarnikjoo et al., 2018), identification and analysis of reverse logistics barriers (Bouzon et al., 2016), developing indicators for sustainable campuses (Chen et al. 2018), selecting road safety performance indicators (Ma et al., 2011), assessing the effectiveness of community-promoted environmental protection policy (Hsueh, 2015). Apart from the delphi based fuzzy approach, studies determining the criteria weight using the MCDM method have been conducted (Stanković et al., 2019, Janković and Popović, 2019).

The rough set theory was first introduced by Pawlak (1982) which is a proper tool for capturing the uncertainties and inaccuracies without subjectivity. They have been successfully utilised in many different areas (Song et al., 2014, Zhai et al., 2010, Pawlak, 2012). The fuzzy sets are a very powerful and widely used tool for handling imprecision. On the other hand, interval-valued fuzzy sets are characterized by the subjectivity of defining the boundaries of sets (which could significantly affect the final decision (Song et al., 2014).) and footprint of uncertainty similar to the type-1 fuzzy sets. To eliminate this subjectivity, we propose interval-valued fuzzy-rough numbers (IVFRN) to take advantage of both fuzzy sets and rough numbers. IVFRN eliminates the disadvantages of type- 1 and interval-valued fuzzy sets. In the IVFRN approach, the borders are determined on the basis of border approximation areas and the uncertainties/imprecision that manage them. This approach uses only internal information, i.e., operative data, and is not based on assumption models. In other words, in the IVFRN implementation, only the structure of the given data is used instead of different additional / external parameters (Pamučar et al. 2018). 


\subsection{Criteria for Offshore Wind Farm Site Selection}

There are various criteria in the scientific literature to evaluate the suitability of sites for installing an OWF. In this study, we have considered 42 criteria of them for the site selection of OWFs, as presented in Table 1. Each criterion is explained in the following subsections. 
Table 1: Offshore wind farm site selection criteria from literature.

\begin{tabular}{|c|c|c|}
\hline No & Criteria & Authors \\
\hline \multirow[t]{2}{*}{$\mathrm{C}$ C1 } & \multirow[t]{2}{*}{ Wind speed } & Vasileiou et al. 2017: Wu et al. 2016): Kim et al. 2013; \\
\hline & & Lynch et al. 2012; ; Schillings et al. 2012, \\
\hline $\mathrm{C} 2$ & Wind directions & Ho et al. 2018) \\
\hline $\mathrm{C} 3$ & Wind power density & Wu et al. 2016:; Fetanat and Khorasaninejad 2015: Kim et al. 2013, 2016; : Punt et al. 2009, \\
\hline $\mathrm{C} 4$ & Wind resource availability & 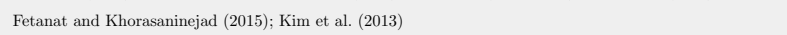 \\
\hline $\mathrm{C} 5$ & Effective wind duration (in hours) & Wu et al. 2016 \\
\hline $\mathrm{C} 6$ & Extreme weather conditions & Kim et al. 2013 \\
\hline $\mathrm{C} 7$ & Operation lifetime (in years) & Kim et al. 2018 \\
\hline $\mathrm{C} 8$ & Total project pay back period & Wu et al. 2016. \\
\hline C9 & Expected benefit to cost ratio & Wu et al. 2016; ;etanat and Khorasaninejad 2015, \\
\hline $\mathrm{C} 10$ & Operating revenue & Ho et al. 2018. \\
\hline $\mathrm{C} 11$ & Investment cost & Wu et al. 2016): Chaouachi et al. 2017); Fetanat and Khorasaninejad 2015): Kim et al. 2018, \\
\hline & & Möller 2011: Punt et al. 2009. \\
\hline $\mathrm{C} 12$ & Operation and maintenance costs & Wu et al. 2016: $\quad$ Kim et al. 2018); Ho et al. 2018;: Möller 2011: : Punt et al. 2009) \\
\hline $\mathrm{C} 13$ & Wave energy potential & Vasileiou et al. 2017. \\
\hline $\mathrm{C} 14$ & Wave height and period & Fetanat and Khorasaninejad 2015: Kim et al. 2013); Ho et al. 2018); Schillings et al. 2012, \\
\hline $\mathrm{C} 15$ & Tidal range and current velocity & \begin{tabular}{|l|l|} 
Kim et al. 2013); & Schillings et al. 2012, \\
\end{tabular} \\
\hline $\mathrm{C} 16$ & Water depth & Vasileiou et al. 2017; $\quad$ Wu et al. 2016); Kim et al. 2013, 2016); Ho et al. 2018); Lynch et al. 2012, \\
\hline & & Schillings et al. 2012) \\
\hline $\mathrm{C} 17$ & Soil conditions & 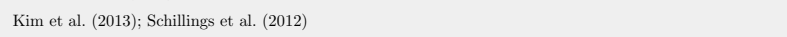 \\
\hline $\mathrm{C} 18$ & Being a typhoon and/or earthquake region & Kim et al. 2013 \\
\hline $\mathrm{C} 19$ & Proximity to the shore & Vasileiou et al. 2017: Wu et al. 2016: Kim et al. 2013, 2016: Mekonnen and Gorsevski 2015, \\
\hline & & Vagiona and Karanikolas 2012;; Ho et al. 2018); Lynch et al. 2012); Schillings et al. 2012, \\
\hline $\mathrm{C} 20$ & Proximity to landscape protection area & Kim et al. 2016. \\
\hline $\mathrm{C} 21$ & Proximity to the WF construction facilities & Fetanat and Khorasaninejad 2015 \\
\hline $\mathrm{C} 22$ & Electricity transmission cable installation cost & Kim et al. 2016, 2018: Mekonnen and Gorsevski 2015: Möller 2011: \\
\hline $\mathrm{C} 23$ & Proximity to grid connections & Vasileiou et al. 2017: Wu et al. 2016; ; Fetanat and Khorasaninejad 2015: Kim et al. 2013, 2016, 2018; \\
\hline & & Vagiona and Karanikolas 2012); Ho et al. 2018); Lynch et al. 2012); Schillings et al. 2012, \\
\hline $\mathrm{C} 24$ & Proximity to the electricity demand region & Fetanat and Khorasaninejad 2015): Mekonnen and Gorsevski 2015: Ho et al. 2018) \\
\hline $\mathrm{C} 25$ & Proximity to the shipping density/congestion & Vasileiou et al. 2017: Wu et al. 2016; : Lynch et al. 2012: Möller 2011: Schillings et al. 2012, \\
\hline $\mathrm{C} 26$ & Proximity to shipping lanes & Kim et al. 2016: Vagiona and Karanikolas 2012: Ho et al. 2018: Schillings et al. 2012, \\
\hline $\mathrm{C} 27$ & Proximity to ports/harbor & 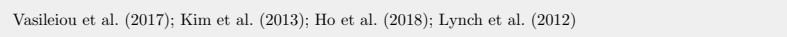 \\
\hline $\mathrm{C} 28$ & Proximity to navigable waterways & Mekonnen and Gorsevski 2015; Ho et al. 2018 \\
\hline C29 & Proximity to conservation area & Kim et al. 2016: Vagiona and Karanikolas 2012: Möller 2011: Schillings et al. 2012, \\
\hline C30 & Effects of wind farm on marine life & Fetanat and Khorasaninejad 2015: Bailey et al. 2014 \\
\hline $\mathrm{C} 31$ & Proximity to passage route of birds & Kim et al. 2013, 2016; : Mekonnen and Gorsevski 2015;: Möller 2011); Punt et al. 2009) \\
\hline & & Bailey et al. 2014 \\
\hline $\mathrm{C} 32$ & Proximity to contaminated/obstructed area & Kim et al. 2016 \\
\hline $\mathrm{C} 33$ & Proximity to military operation area & Vasileiou et al. 2017); Wu et al. 2016); Kim et al. 2013, 2016; ; Ho et al. 2018); Möller 2011, \\
\hline & & Schillings et al. 2012) \\
\hline $\mathrm{C} 34$ & Proximity to radio and radar corridors & Fetanat and Khorasaninejad 2015: Ho et al. 2018: Lynch et al. 2012): Möller 2011) \\
\hline $\mathrm{C} 35$ & Economic externalities & Fetanat and Khorasaninejad 2015 \\
\hline $\mathrm{C} 36$ & Local economic benefits (employment) & Wu et al. 2016): Fetanat and Khorasaninejad 2015: Ho et al. 2018 \\
\hline C37 & Proximity to the hydrocarbon reserves & 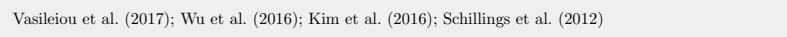 \\
\hline $\mathrm{C} 38$ & Investment incentives & Wu et al. 2016;: Ho et al. 2018): Lynch et al. 2012, \\
\hline C39 & Production incentives & Ho et al. 2018. \\
\hline $\mathrm{C} 40$ & Feed-in-tariff for offshore wind energy & Ho et al. 2018 \\
\hline $\mathrm{C} 41$ & Community/local acceptance & Fetanat and Khorasaninejad 2015: Ho et al. 2018: \\
\hline $\mathrm{C} 42$ & Wind farm size (in terms of capacity in MW) & Kim et al. 2018 \\
\hline
\end{tabular}

\subsubsection{Wind speed}

As expected, the wind speed is an important factor for the amount of energy a wind turbine can convert to electrical power. The power generated by a wind turbine varies with the cube of the wind speed. Due to torque limitations, a 
wind turbine is designed to generate power over a limited range of wind speeds, starting with a cut-in speed (ca. 3-4 m/s) and ending with a cut-out speed (ca. $25 \mathrm{~m} / \mathrm{s}$ ). At high wind speeds wind turbines stop or employ other mechanism to limit the high torque. Offshore wind speeds tend to be faster and less turbulent than on land. Wind shade (wind speed behind an obstacle - e.g. a hill) is a factor that should be considered since it influences offshore farms that are too close to the shore.

\subsubsection{Wind directions}

Although a wind turbine's nacelle can rotate to face the current wind direction, a rapidly changing wind direction affects the efficiency of the turbine - the turbine is not able to follow the rapid changes in direction. At low to medium wind speeds the presence of a yaw angle significantly reduces the power output. Locations with a predictable wind direction should be prioritised.

\subsubsection{Wind power density (WPD)}

The product obtained by multiplying the power of each wind speed with the probability of each wind speed appearing is named wind power density. In other words it is the quantity of energy produced by various wind speeds. Turbines that are deployed at sites having higher WPD generate more energy. WPD also depends on air density (generally constant), atmospheric pressure and temperature.

\subsubsection{Wind resource availability}

Overall for a wind farm it is more desirable to have a constant power output (even if at lower power ranges) than long alternating periods of high power output (could trigger the cut out limit) and no power output (under cut in limit) - e.g. major seasonal changes. The wind availability should be as much as possible correlated with the energy demand in the power system. 


\subsubsection{Effective wind duration (in hours)}

This criterion refers to effective wind hours that accumulate in one year $\mathrm{Wu}$ et al. (2016). Generally, it is not a primary parameter. Effective wind hours may be dependent on country-settings and the tariffs, but they do not vary much in the sea regime.

\subsubsection{Extreme weather conditions}

Just as for onshore wind farms, extreme weather conditions can also damage offshore farms. Wind turbines are designed to output power within a predefined range of wind speeds. Electricity generation increases with wind speed until it reaches a limit (rated speed), followed by a cut-out speed where the turbine stops (to prevent damage to the rotor). Frequent storms or high winds, that keep the wind farm in cut-out mode, bring a negative impact on the profitability of the installation.

\subsubsection{Operation lifetime (in years)}

The lifespan of a wind turbine depends on its size and location and varies from 15 to 25 years. A offshore wind farm will have a longer lifespan due to the lower fatigue loads on the wind turbines (low turbulence at sea). In the end, it is not clear what is the exact lifetime of a wind farm - as of today few if any have been refurbished or decommissioned.

\subsubsection{Total project pay back period}

The pay back period is the time required to recover the investment plus the operational costs. The main factor influencing this period is the scale of the project. Although they generate a lot more energy, Offshore wind farms need a longer period to reach the break-even point compared to onshore farms due to the large investment costs. The pay back period could also be seen from the environmental point of view (emitted $\mathrm{CO}_{2}$ and energy consumption during the manufacture of the turbine). 


\subsubsection{Expected benefit to cost ratio}

The cost-benefit ratio shows the relationship between the relative monetary value and benefits of a project. If the benefit is higher than the cost (ratio higher than 1) the project is a good investment. For Wind farms, estimating the cost-benefit ratio is complex since they play a role in climate change (it is hard to estimate the monetary benefits).

\subsubsection{Operating revenue}

The operating revenue is one of the first factors to be considered when planning a new installation. Calculating the revenue is rather complex since a Wind farm: is a intermittent power generator, receives or not financial support (e.g. feed-in tariffs, environmental credits, capacity credits), might see occurrences of zero or even negative energy prices and reactive power charges.

\subsubsection{Investment cost}

The installation of an offshore wind farm is much more complex than for onshore installations (scale, location, anchoring to the seabed, transportation, connection to grid, corrosive conditions etc.) However, the scale of offshore wind farms is generally larger compared to onshore wind farms and the turbines themselves are also larger. The economies of scale lower the costs per installed MW for offshore wind turbines, but not enough to be comparable to onshore wind turbines. Additionally, the planning and permitting phase for offshore wind farms is tedious and more expensive.

\subsubsection{Operation and maintenance costs}

Offshore wind farms maintenance is much more costly compared to onshore installations due to the location accessibility, weather conditions, personnel qualification, multiple transportation means, health-monitoring systems,

maintenance teams living on site etc. Moreover, the corrosive nature of the environment requires a higher maintenance frequency. 


\subsubsection{Wave energy potential}

Although not seen at a large scale, a high wave potential energy could allow a combination of offshore wind farms and wave energy farms. In the future, some of the existing farms could be retrofitted to include a wave energy option. In some cases waves can damage the wind park, either because the brute force of the waves or fatigue (wind still contributes most to the fatigue load).

\subsubsection{Wave height and period}

High waves limit the access to the wind farm for maintenance directly increasing the operation and maintenance costs. In extreme cases they can damage the turbines themselves (brute force or fatigue).

\subsubsection{Tidal range and current velocity}

Combining wind and tidal/current stream turbines in the same farm improves the efficiency of the installation. However, the investment costs could be too high to justify the improved efficiency. In areas with extreme tides, the rise and fall of the sea due to the tide changes the wind shear profile around the turbines. This might slightly affect the efficiency of the wind farm.

\subsubsection{Water depth}

Regarding the location bathymetry, the general consensus is that for depths over $60 \mathrm{~m}$, a fixed foundation is unfeasible and a floating solution is needed. As of today, beyond this depth the investment and operation costs of the offshore wind farms would be too large for the farm to be profitable.

\subsubsection{Soil conditions}

The seabed (soil) supports or anchors the foundation of the turbines, transferring and absorbing the loads (weight, vibrations, wind, waves, rotor frequency etc.) of the installations. It also support the connecting cables. The relief of the seafloor (including how fast in changes) and the geology of the location are very important in an offshore farm, the foundations costing ca. $30 \%$ of the overall project. 


\subsubsection{Being a typhoon and/or earthquake region}

As expected, zones prone to natural disasters should be avoided when considering a new wind farm project. In some cases where there is no way to avoid this (e.g. countries that are fully exposed to these natural phenomena) the wind farms must be engineered to be survive these harsh conditions - this increasing the investment costs.

\subsubsection{Proximity to the shore (Noise, visual impact etc.)}

Building an offshore wind farm too close to the shore may be unpopular with local residents, and may influence negatively property values and/or tourism. At $1.5 \mathrm{~km}$ distance most wind turbines become inaudible. Wind power stations installed close to urbanized and industrial regions seem to have less of an impact.

\subsubsection{Proximity to the landscape protection area}

Landscape protection areas must be treated with special attention and in most cases extra steps are required to receive the construction permits for the wind farms. Extra environmental audits or more frequent maintenance might be mandatory during the lifetime of the project, with risks of shutting down the farm earlier than expected (e.g. new legislation). All this translates to a direct economic impact for the project.

\subsubsection{Proximity to the facilities for wind farm construction}

Deploying the farm closer to a construction facility is an economic advantage since the transportation logistic is somewhat simpler. This could allow larger turbines to be built.

\subsubsection{Electricity transmission cable installation cost}

The cable and cable installation costs are much higher for offshore wind farm since special cables and cable-laying vessels are used. Repairing such a cable is also costly procedure with longer farm unavailability times. Undersea cables will have to be buried in order to reduce the risk of damage. 


\subsubsection{Proximity to the grid connections}

A offshore wind farm that is close to a grid connection has some major advantages: shorter connecting cables, less energy loss, lower reactive power, no need for extra electrical substations etc. High-voltage direct current (HVDC) transmission presents lower losses in exchange for a larger investment.

\subsubsection{Proximity to the electricity demand region}

If the offshore farm is far from the region that consumes the generated energy, grid reinforcements are necessary - to move the extra power and to limit the negative effect of the variable power on the regions that are closer to the farm. This is a significant investment and it affects the power grid operator.

\subsubsection{Proximity to the shipping density/congestion}

Building next to or in a congested area could be prohibited. If not, the accident risk is higher both for the offshore wind farm and the installation/maintenance vessels.

\subsubsection{Proximity to the shipping lanes}

Current legislation may limit the proximity to shipping lanes or favor shipping lanes over wind farms. However, for some cases altering shipping routes for offshore wind development could prove financially beneficial. In some countries navigation within the borders of a wind farm is permitted.

\subsection{2\%. Proximity to the ports/harbor}

This is a financial advantage both for the installation and the maintenance vessels: shorter trips, shorter down-times etc.). It has also a downside since the farm is closer to a congested area.

\subsubsection{Proximity to the navigable waterways}

If not extremely busy, being close to a navigable waterway is a logistic advantage for the installation and maintenance vessels since the trips on land are minimised. 


\subsubsection{Proximity to the natural environment conservation area}

Similarly to the landscape protected areas, special attention and inmost cases extra steps are required to receive the construction permits for the offshore wind farms. Extra environmental audits or more frequent maintenance might be mandatory during the lifetime of the project, with risks of shutting down the farm earlier than expected. As of today, the effects on marine life are not fully understood.

2.3.30. Effects of wind farm on marine life (marine animals) during and after its installation

Due to the large scale of the farms a change in the local environment is present, however, the effects on marine life are not fully understood at the moment. The environmental impact of wind power when compared to the environmental impacts of fossil fuels, is relatively minor.

\subsubsection{Proximity to the passage route of birds}

There are reports of bird mortality at wind turbines but the numbers seem to be comparable to mortality due to collisions with buildings. Impacts are very site-dependent. The scale of the ecological impact is not fully understood, however birds may to consume more energy for additional flights due to the interference of the turbines.

\subsubsection{Proximity to the contaminated/obstructed area}

Activities that have caused environmental pollution have been conducted in the world for a very long time. A wind farm close or within a contaminated area can be dangerous and/or offer limited access for the construction and maintenance teams. Extra costs may be needed for environmental monitoring activities.

\subsubsection{Proximity to military operation area}

If the wind farm is located close to low-level military operation areas, a military requirement for infra-red lighting is noted next to the standard aviation 
active and passive markings. Additional training should be provided to the agencies operating in the area and if needed restrictions or mitigation actions should be applied (e.g. prohibit flights under a certain altitude).

\subsubsection{Proximity to radio and radar corridors (impact on aviation)}

Large wind farms can have a significant effect on radars used for aviation, as they are typically designed to show only moving objects. The spinning blades of the wind turbines can appear on the radar screen. Blade material, blade shape and turbine height are the factors determining how much a turbine affects radar equipment. There are a series of mitigation factors that need to be implemented to ensure successful coexistence between wind farms and radio/radar corridors.

\subsubsection{Economic externalities}

An externality is an economic term referring to a negative or positive effect over a third party who has no control over it. For example a wind farm can increase or decrease electricity prices, can influence the housing market, can bring environmental benefits to an area etc. Renewable energies have external costs that are overall lower compared to other energy generation technologies.

\subsubsection{Local economic benefits (employment)}

An offshore wind farm will bring local economic benefits such as new jobs, higher wages or increasing the tax bases for the neighbouring localities.

\subsubsection{Proximity to the hydrocarbon reserves}

Hydrocarbon reserves in the proximity of the wind farms could be seen as a plus. In the area there already is infrastructure and experience for the construction and maintenance of offshore equipment. On the other hand tensions could appear between the two industrial sectors.

\subsubsection{Investment incentives}

The need for energy diversification and lower greenhouse gas emissions drive the construction of new wind farms. Certain regions or countries encourage 
investment in offshore wind farms either financially (e.g. tax credits, partial funding etc.) or legislatively (e.g. streamlining the permitting phase, creating frameworks for collaboration between multiple parties etc.)

\subsubsection{Production incentives}

Local or national authorities can open programs that incentive wind power generation: paying excess generation costs, tax credits, blocking curtailment, giving priority over other energy sources etc.

\subsubsection{Feed-in-tariff for offshore wind energy}

A feed-in-tariff is a mechanism that encourages investment in renewable energy technologies, in this case in offshore wind farms. Guaranteed grid access, long-term contracts, cost-based purchase prices are all methods to achieve this.

\subsubsection{Community/local acceptance}

It is a matter of taste how people perceive that wind turbines and there is no absolute clear conclusion regarding the social acceptance of offshore wind power compared to onshore. Offshore wind farms are generally accepted by tourists and locals if they are situated farther from the coastline.

\subsubsection{Wind farm size (in terms of capacity in $M W$ )}

Due to the economies of scale, the larger the wind farm and the wind turbines, the lower the investment per installed MW. However, large wind farms bring a a wide array of technical, logistical and/or legislative issues, one of them being the connection and interaction with the local power grid (and power plants). Major grid reinforcements are generally needed.

\section{Preliminaries}

\subsection{Interval-valued Fuzzy-rough Numbers}

Based on the ideas of Zadeh (1965) and Pawlak (1982), the mathematical definition of the interval-valued fuzzy-rough numbers is presented in 2018, 
Pamučar et al. (2018). Since then, IVFRN using different notations have been studied by several authors. The definitions of IVFRN are given by Pamučar et al. (2018) as follows:

We will define fuzzy set as a set of ordered pairs $A=\left\{\left(x,\left(\mu_{A}(x)\right) \mid x \in\right.\right.$ $\left.X, 0 \leq \mu_{A}(x) \leq 1\right\}$ which is described by means of a triangular membership function. Then we can represent fuzzy number $A$ as $A=\left(a_{1}, a_{2}, a_{3}\right)$, where $a_{1}$ and $a_{3}$ respectively represent the left and right limits of the interval of fuzzy number $A$, and $a_{2}$ represents the modal value (see Fig 1 ).

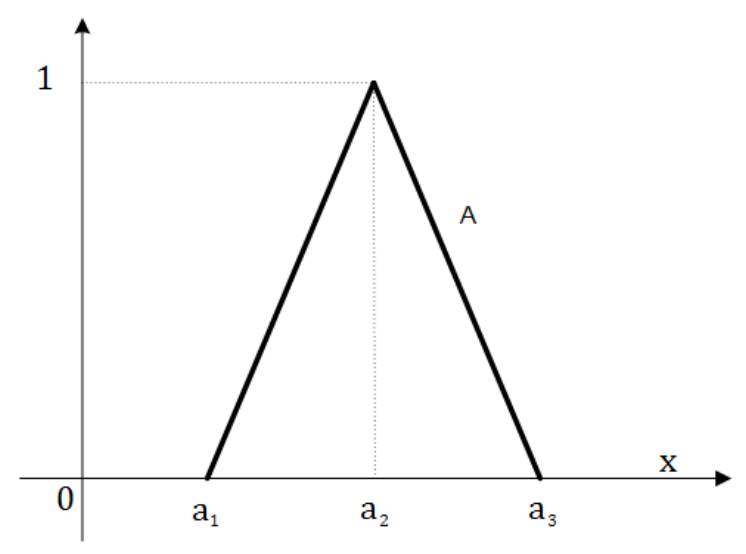

Figure 1: Type-1 fuzzy number.

We assume that $U$ universe contains all of the objects and let $Y$ be an arbitrary object from $U$. We assume there is a set of $k$ classes which represent the preferences of the DM, $G^{*}=\left(A_{1}, A_{2}, \ldots, A_{k}\right)$, with the condition that they belong to a series which satisfies the condition $A_{1}<A_{2}<, \ldots,<A_{k}$. All objects are defined in the universe and connected with the preferences of the Decision Maker (DM). Each element $A_{i}=(1 \leq i \leq k)$ represents a fuzzy number that is defined as $A_{q}=\left(a_{1 q}, a_{2 q}, a_{3 q}\right)$.

Since element $A_{i}$ from the class of objects $G^{*}$ is represented as fuzzy number $A_{q}=\left(a_{1 q}, a_{2 q}, a_{3 q}\right)$, for each value $a_{1 q}, a_{2 q}$, and $a_{3 q}$ we obtain one class of objects that is represented in the interval $I\left(a_{j}\right)_{q}=\left\{I\left(a_{j}\right)_{l q}, I\left(a_{j}\right)_{u q}\right\}(j=1,2,3)$ where the condition is fulfilled that $I\left(a_{j}\right)_{l q} \leq I\left(a_{j}\right)_{u q}(1 \leq q \leq k)$, as well as the 
condition $I\left(a_{j}\right)_{q} \in G^{*}$. Then $I\left(a_{j}\right)_{l q}$ and $I\left(a_{j}\right)_{u q}$ respectively represent the lower and upper border of the intervals of the $q$-th class of objects.

If both limits of the classes of objects (upper and lower limits) respectively are compared so that $I^{*}\left(a_{j}\right)_{l 1}<I^{*}\left(a_{j}\right)_{l 2}<, \ldots,<I^{*}\left(a_{j}\right)_{l s} ; I^{*}\left(a_{j}\right)_{u 1}<$ $I^{*}\left(a_{j}\right)_{u 2}<, \ldots,<I^{*}\left(a_{j}\right)_{u m}(1 \leq s, m \leq k)$, then for any of the classes of objects $I^{*}\left(a_{j}\right)_{l q} \in G^{*}$ and $I^{*}\left(a_{j}\right)_{u q} \in G^{*}$ we can define the lower approximation $I^{*}\left(a_{j}\right)_{l q}$ using the following equations:

$$
\underline{\operatorname{Apr}}\left(I^{*}\left(a_{j}\right)_{l q}\right)=\cup\left\{Y \in U / G^{*}(Y) \leq I^{*}\left(a_{j}\right)_{l q}\right\} ;(j=1,2,3 ; \quad 1 \leq q \leq k)
$$

And the upper approximation of $I^{*}\left(a_{j}\right)_{u q}$ using the following equations:

$$
\overline{\operatorname{Apr}}\left(I^{*}\left(a_{j}\right)_{u q}\right)=\cup\left\{Y \in U / G^{*}(Y) \leq I^{*}\left(a_{j}\right)_{u q}\right\} ;(j=1,2,3 ; \quad 1 \leq q \leq k)
$$

Both classes of objects (object classes $I^{*}\left(a_{j}\right)_{l q}$ and $\left.I^{*}\left(a_{j}\right)_{u q}\right)$ are defined by their lower limits $\underline{\operatorname{Lim}}\left(I^{*}\left(a_{j}\right)_{l q}\right)$, and upper limits $\overline{\operatorname{Lim}}\left(I^{*}\left(a_{j}\right)_{u q}\right)$. The lower limits are defined by the following equations:

$$
\underline{\operatorname{Lim}}\left(I^{*}\left(a_{j}\right)_{l q}\right)=\frac{1}{M_{L}\left(a_{j}\right)} \sum G^{*}(Y) \mid Y \in \underline{A p r}\left(I^{*}\left(a_{j}\right)_{l q}\right) ;(1 \leq q \leq k)
$$

where $M_{L}\left(a_{j}\right)$ represents the number of objects included in the lower approximation of the classes of object $I^{*}\left(a_{j}\right)_{l q}$ The upper limits $\overline{\operatorname{Lim}}\left(I^{*}\left(a_{j}\right)_{u q}\right)(j=$ $1,2,3)$ are defined by the following equations:

$$
\overline{\operatorname{Lim}}\left(I^{*}\left(a_{j}\right)_{u q}\right)=\frac{1}{M_{U}\left(a_{j}\right)} \sum G^{*}(Y) \mid Y \in \overline{\operatorname{Apr}}\left(I^{*}\left(a_{j}\right)_{u q}\right) ;(1 \leq q \leq k)
$$

where $M_{U}\left(a_{j}\right)(j=1,2,3)$ represents the number of objects that are contained in the upper approximation of the classes of object $I^{*}\left(a_{j}\right)_{u q}$. Eqs. (1)-(4) are used in Section 5 for transformation of the experts fuzzy preferences into IVFRNs. Both limits of the objects (lower limit and upper limit) $\underline{\operatorname{Lim}}\left(I^{*}\left(a_{j}\right)_{l q}\right)$ and $\overline{\operatorname{Lim}}\left(I^{*}\left(a_{j}\right)_{u q}\right) ; j=1,2,3$ should satisfy the condition that

$$
\underline{\operatorname{Lim}}\left(I^{*}\left(a_{1}\right)_{l q}\right) \leq \overline{\operatorname{Lim}}\left(I^{*}\left(a_{1}\right)_{u q}\right) \leq \underline{\operatorname{Lim}}\left(I^{*}\left(a_{2}\right)_{l q}\right) \leq \overline{\operatorname{Lim}}\left(I^{*}\left(a_{2}\right)_{u q}\right) \leq \underline{\operatorname{Lim}}\left(I^{*}\left(a_{3}\right)_{l q}\right) \leq \overline{\operatorname{Lim}}\left(I^{*}\left(a_{3}\right)_{u q}\right)
$$

If due to higher uncertainty (disagreement) in the expert decision making and characteristics of the predefined fuzzy linguistic scales condition (Eq. 5) 
is not fulfilled, that is $\overline{\operatorname{Lim}}\left(I^{*}\left(a_{1}\right)_{u q}\right)>\underline{\operatorname{Lim}}\left(I^{*}\left(a_{2}\right)_{l q}\right)$ or $\overline{\operatorname{Lim}}\left(I^{*}\left(a_{2}\right)_{u q}\right)>$ $\underline{\operatorname{Lim}}\left(I^{*}\left(a_{3}\right)_{l q}\right)$, then Eqs. (6) and (7) apply

$$
\begin{aligned}
& \overline{\operatorname{Lim}}\left(I^{*}\left(a_{1}\right)_{u q}\right)=\underline{\operatorname{Lim}}\left(I^{*}\left(a_{2}\right)_{l q}\right) \\
& \underline{\operatorname{Lim}}\left(I^{*}\left(a_{3}\right)_{l q}\right)=\overline{\operatorname{Lim}}\left(I^{*}\left(a_{2}\right)_{u q}\right)
\end{aligned}
$$

For each class of objects we can determine a rough boundary interval of $I\left(a_{1}\right)_{q}$ represented as $R B\left(I\left(a_{j}\right)_{q}\right)$, which denotes the interval between the lower and upper limit:

$$
R B\left(I\left(a_{1}\right)_{q}\right)=\overline{\operatorname{Lim}}\left(I^{*}\left(a_{1}\right)_{u q}\right)-\underline{\operatorname{Lim}}\left(I^{*}\left(a_{2}\right)_{l q}\right) ;(j=1,2,3 ; 1 \leq q \leq k)
$$

As we see, each class of objects $I\left(a_{1}\right)_{q}, I\left(a_{2}\right)_{q}$ and $I\left(a_{3}\right)_{q}$ is defined by means of its own lower and upper limits, which make up the interval fuzzyrough number $(\overline{\bar{A}})$ Fig. 2 defined as

$$
\overline{\bar{A}}=\left[A_{q}^{L}, A_{q}^{U}\right]=\left[\begin{array}{l}
\overline{\operatorname{Lim}}\left(I^{*}\left(a_{1}\right)_{u q}\right), \underline{\operatorname{Lim}}\left(I^{*}\left(a_{2}\right)_{l q}\right), \overline{\operatorname{Lim}}\left(I^{*}\left(a_{2}\right)_{u q}\right), \underline{\operatorname{Lim}}\left(I^{*}\left(a_{3}\right)_{l q}\right) ; w_{1}\left(A_{q}^{L}\right) \\
\underline{\operatorname{Lim}}\left(I^{*}\left(a_{1}\right)_{l q}\right), \underline{\operatorname{Lim}}\left(I^{*}\left(a_{2}\right)_{l q}\right), \overline{\operatorname{Lim}}\left(I^{*}\left(a_{2}\right)_{u q}\right), \overline{\operatorname{Lim}}\left(I^{*}\left(a_{3}\right)_{l q}\right) ; w_{1}\left(A_{q}^{U}\right)
\end{array}\right]
$$

where $A_{q}^{L}$ and $A_{q}^{U}$ respectively represent the upper and lower trapezoidal fuzzy-rough number which meets the condition that $A_{q}^{L} \subset A_{q}^{U}$, while $w_{1}\left(A_{q}^{L}\right)$ and $w_{2}\left(A_{q}^{U}\right)$ respectively represent the maximum values of interval fuzzy-rough number $\overline{\bar{A}}$.

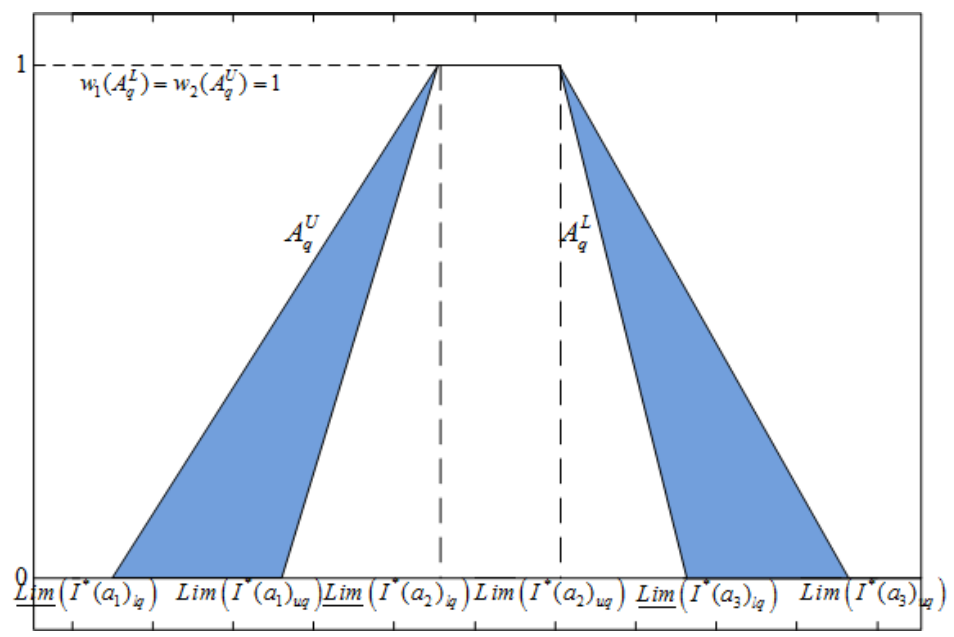

Figure 2: Interval fuzzy-rough number $\overline{\bar{A}}$. 
From Fig. 2 we observe that for interval-valued fuzzy-rough number $\overline{\bar{A}}$ it is valid that $w_{1}\left(A_{q}^{L}\right)=w_{2}\left(A_{q}^{U}\right)=1$. On this basis we can write Eq. 9 in the following form:

$$
\overline{\bar{A}}=\left[A_{q}^{L}, A_{q}^{U}\right]=\left[\left(a_{1 q}^{L}, a_{1 q}^{U}\right),\left(a_{2 q}^{L}, a_{2 q}^{U}\right),\left(a_{3 q}^{L}, a_{3 q}^{U}\right)\right]
$$

where $a_{j q}^{L}=\underline{\operatorname{Lim}}\left(I^{*}\left(a_{j}\right)_{l q}\right)$ and $a_{j q}^{U}=\overline{\operatorname{Lim}}\left(I^{*}\left(a_{j}\right)_{u q}\right) ;(j=1,2,3 ; 1 \leq q \leq$ k)

If there is consensus among the decision makers on the assignment of specific values from the linguistic fuzzy scale then $a_{1 q}^{L}=a_{1 q}^{U}, a_{2 q}^{L}=a_{2 q}^{U}$ and $a_{3 q}^{L}=a_{3 q}^{U}$. Then interval-valued fuzzy-rough number $\overline{\bar{A}}$ becomes fuzzy number $A$ type-1.

Interval-valued fuzzy-rough number $\overline{\bar{A}}$ defined at the interval $(-\infty,+\infty)$ can be represented using Eqs. 111 and 12

$$
\begin{gathered}
\overline{\bar{A}}=\left\{x\left[\mu_{A_{q}^{L}}(x), \mu_{A_{q}^{U}}(x)\right]\right\}, x \in(-\infty,+\infty), \quad \mu_{A_{q}^{L}}(x), \mu_{A_{q}^{U}}(x):(-\infty,+\infty) \rightarrow[0,1] \\
\mu_{\overline{\bar{A}}}(x)=\left[\mu_{A_{q}^{L}}(x), \mu_{A_{q}^{U}}(x)\right], \quad \mu_{A_{q}^{L}}(x) \leq \mu_{A_{q}^{U}}(x), \quad \forall x \in(-\infty,+\infty)
\end{gathered}
$$

where $\mu_{A_{q}^{L}}(x)$ and $\mu_{A_{q}^{U}}(x)$ represent the degree of membership in the upper and lower functions of interval-valued fuzzy-rough number $\overline{\bar{A}}$.

Based on the above we can define arithmetic operations between two interval-valued fuzzy-rough numbers $\overline{\bar{A}}=\left[\left(a_{1}^{L}, a_{1}^{U}\right),\left(a_{2}^{L}, a_{2}^{U}\right),\left(a_{3}^{L}, a_{3}^{U}\right)\right], \overline{\bar{B}}=$ $\left[\left(b_{1}^{L}, b_{1}^{U}\right),\left(b_{2}^{L}, b_{2}^{U}\right),\left(b_{3}^{L}, b_{3}^{U}\right)\right]$ :

Addition of interval-valued fuzzy-rough numbers " +"

$$
\begin{array}{r}
\overline{\bar{A}}+\overline{\bar{B}}=\left[\left(a_{1}^{L}, a_{1}^{U}\right),\left(a_{2}^{L}, a_{2}^{L}\right),\left(a_{3}^{L}, a_{3}^{U}\right)\right]+\left[\left(b_{1}^{L}, b_{1}^{U}\right),\left(b_{2}^{L}, b_{2}^{U}\right),\left(b_{3}^{L}, b_{3}^{U}\right)\right] \\
=\left[\left(a_{1}^{U}+b_{1}^{U}\right),\left(a_{1}^{L}+b_{1}^{U}\right),\left(a_{2}^{L}+b_{2}^{L}, a_{2}^{U}+b_{2}^{U}\right),\left(a_{3}^{L}+b_{3}^{L}, a_{3}^{U}+b_{3}^{U}\right)\right]
\end{array}
$$

Operations subtraction $(-)$, multiplication $(\times)$ and division $(\div)$ are defined in the same way (Pamučar et al. 2018$)$. These basic operations on IVFRN numbers are used for calculations in IVFRN LBWA model, Section 5 


\subsection{Interval-valued Fuzzy-rough Delphi Method}

In this study, we combine IVFRN and classic Delphi method to address imprecision, vagueness and uncertainty of judgments for the group decisionmaking process. The schematic diagram of proposed model is shown in Fig. 3 The steps of proposed method are given as follows:

Step 1: The experts' opinions are gathered from the questionnaires for each criterion. Under the assumption that there are $m$ experts and $n$ criteria under consideration, each expert should determine the degree of preference of the criterion $C_{i}(i=1,2, \ldots, n)$. The fuzzy preference of each criterion $i$, denoted as $\tilde{a}_{i}$ is defined based on predefined fuzzy scale. Based on the fuzzy preferences of the experts' answers, for each element $l_{i}^{e}, s_{i}^{e}$ and $u_{i}^{e}$ of fuzzy number $a_{i}^{e}=$ $\left(l_{i}^{e}, s_{i}^{e}, u_{i}^{e}\right)$ we form vectors of the aggregated sequences of experts $A^{* e l}, A^{* e s}$ and $A^{* e u}$

$$
\begin{gathered}
A^{* e l}=\left[l_{1}^{1}, l_{1}^{2}, \ldots, l_{1}^{m} ; \quad l_{2}^{1} ; l_{2}^{2} ; \ldots ; l_{2}^{m}, \ldots, \quad l_{n}^{1} ; l_{n}^{2}, \ldots, l_{n}^{m}\right]_{1 \times n} \\
A^{* e s}=\left[s_{1}^{1}, s_{1}^{2}, \ldots, s_{1}^{m} ; \quad s_{2}^{1} ; s_{2}^{2} ; \ldots ; s_{2}^{m}, \ldots, \quad s_{n}^{1} ; s_{n}^{2}, \ldots, s_{n}^{m}\right]_{1 \times n} \\
A^{* e u}=\left[u_{1}^{1}, u_{1}^{2}, \ldots, u_{1}^{m} ; \quad u_{2}^{1} ; u_{2}^{2} ; \ldots ; u_{2}^{m}, \ldots, \quad u_{n}^{1} ; u_{n}^{2}, \ldots, u_{n}^{m}\right]_{1 \times n}
\end{gathered}
$$

where $l_{i}^{e}, s_{i}^{e}$ and $u_{i}^{e}$ represent sequences of fuzzy number $a_{i}^{e}=\left(l_{i}^{e}, s_{i}^{e}, u_{i}^{e}\right)$ by means of which the relative significance of criterion $C_{i}$ is presented. Using Eqs. (1)-(7) each sequence $l_{i}^{e}, s_{i}^{e}$ and $u_{i}^{e}$ is transformed into rough sequence $R N\left(l_{i}^{e}\right)=\left[\underline{\operatorname{Lim}}\left(l_{i}^{e}\right), \overline{\operatorname{Lim}}\left(l_{i}^{e}\right)\right], R N\left(s_{i}^{e}\right)=\left[\underline{\operatorname{Lim}}\left(s_{i}^{e}\right), \overline{\operatorname{Lim}}\left(s_{i}^{e}\right)\right]$ and $R N\left(u_{i}^{e}\right)=\left[\underline{\operatorname{Lim}}\left(u_{i}^{e}\right), \overline{\operatorname{Lim}}\left(u_{i}^{e}\right)\right]$, where $\underline{\operatorname{Lim}}\left(l_{i}^{e}\right), \underline{\operatorname{Lim}}\left(s_{i}^{e}\right)$ and $\underline{\operatorname{Lim}}\left(u_{i}^{e}\right)$ represent the lower limits, and $\overline{\operatorname{Lim}}\left(l_{i}^{e}\right), \overline{\operatorname{Lim}}\left(s_{i}^{e}\right)$ and $\overline{\operatorname{Lim}}\left(u_{i}^{e}\right)$ the upper limits of the rough sequences $R N\left(l_{i}^{e}\right), R N\left(s_{i}^{e}\right)$ and $R N\left(u_{i}^{e}\right)$ respectively.

So for each sequence $R N\left(l_{i}^{e}\right), R N\left(s_{i}^{e}\right)$ and $R N\left(u_{i}^{e}\right)$ we obtain a rough vector: for the first rough sequence $A^{* 1 l}, A^{* 2 l}, \ldots, A^{* m l}$ for the second rough sequence $A^{* 1 s}, A^{* 2 s}, \ldots, A^{* m s}$ and for the third rough sequence $A^{* 1 u}, A^{* 2 u}, \ldots, A^{* m u}$. 
Step 2: Determining average rough sequences of the rough vectors. By applying Eqs. 177, 18 and (19) we obtain the average rough sequence of the vector

$$
\begin{gathered}
R N\left(\bar{l}_{i}\right)=R N\left(l_{i}^{1}, l_{i}^{2}, \ldots, l_{i}^{e}\right)\left\{\begin{array}{l}
\bar{l}_{i}^{L}=\frac{1}{m} \sum_{e=1}^{m} l_{i}^{e L} \\
\bar{l}_{i}^{U}=\frac{1}{m} \sum_{e=1}^{m} l_{i}^{e U}
\end{array}\right. \\
R N\left(\bar{s}_{i}\right)=R N\left(s_{i}^{1}, s_{i}^{2}, \ldots, s_{i}^{e}\right)\left\{\begin{array}{l}
\bar{s}_{i}^{L}=\frac{1}{m} \sum_{e=1}^{m} s_{i}^{e L} \\
\bar{s}_{i}^{U}=\frac{1}{m} \sum_{e=1}^{m} s_{i}^{e U}
\end{array}\right. \\
R N\left(\bar{u}_{i}\right)=R N\left(u_{i}^{1}, l_{i}^{2}, \ldots, u_{i}^{e}\right)\left\{\begin{array}{l}
\bar{u}_{i}^{L}=\frac{1}{m} \sum_{e=1}^{m} u_{i}^{e L} \\
\bar{u}_{i}^{U}=\frac{1}{m} \sum_{e=1}^{m} u_{i}^{e U}
\end{array}\right.
\end{gathered}
$$

where $e$ represents the $e$-th expert $(e=1,2, \ldots, n), R N\left(\bar{l}_{i}\right), R N\left(\bar{s}_{i}\right)$ and $R N\left(\bar{u}_{i}\right)$ represent the rough sequences that together make up IVFRN $\overline{\bar{a}}_{i}=$ $\left[\left(\bar{l}_{i}^{L}, \bar{l}_{i}^{U}\right),\left(\bar{s}_{i}^{L}, \bar{s}_{i}^{U}\right),\left(\bar{u}_{i}^{L}, \bar{u}_{i}^{U}\right)\right]$. We thus obtain the averaged IVFRN preferences of average responses $\overline{\bar{A}}=\left[\overline{\bar{a}}_{1}, \overline{\bar{a}}_{2}, \ldots, \overline{\bar{a}}_{n}\right]_{[1 \times n]}$

Step 3: Defuzzify $\overline{\bar{a}}_{i}$ using score function for IVFRN as in following:

$$
d\left(\overline{\bar{a}}_{i}\right)=\left(1+\frac{\bar{l}_{i}^{L}+\bar{u}_{i}^{U}}{2}\right) \cdot\left(\frac{\bar{l}_{i}^{L}+\bar{l}_{i}^{U}+2 \bar{s}_{i}^{L}+2 \bar{s}_{i}^{U}+\bar{u}_{i}^{L}+\bar{u}_{i}^{U}}{8}\right)
$$

where $d\left(\overline{\bar{a}}_{i}\right)$ is a crisp score which denotes the aggregate importance of each criteria.

Step 4: Calculation of the influence function $f: S \rightarrow R$ of the criteria. The influence function is defined in the following way. For every criterion $C_{i}$ can be defined the influence function of the criterion

$$
f\left(C_{i}\right)=\frac{r_{0}}{r_{0}+\max \left\{d\left(\overline{\bar{a}}_{i}\right)\right\}-d\left(\overline{\bar{a}}_{i}\right)} \quad \forall i
$$

where $d\left(\overline{\bar{a}}_{i}\right)$ is a crisp score which denotes the aggregate importance of each criteria and $r_{0}$ presents the elasticity coefficient.

The elasticity coefficient $r_{0} \in N$ (where $N$ presents the set of real numbers) should meet the requirement where $r_{0}>r$, where $r$ represents maximum numbers of criteria on the level (Žižović and Pamucar, 2019). Since we have all criteria on the one level, i.e. $r_{0}=1$, we have $r_{0}>1$. 
Step 5: Calculation of the optimal values of the weight coefficients of the criteria. Let the criterion $C_{1}$ be the criterion in the set of criteria $S=\left\{C_{1}, C_{2}, \ldots, C_{n}\right\}$ that is the most significant for the decision-making process. By applying the Eq. (22) it is calculated the weight coefficient of the most significant criterion:

$$
w_{1}=\frac{1}{1+f\left(C_{2}\right)+\cdots+f\left(C_{n}\right)}
$$

The values of the weight coefficients of the remaining criteria are obtained by applying the Eq. 23)

$$
w_{i}=f\left(C_{i}\right) \cdot w_{1}
$$

where $i=2,3, \ldots, n$, and $n$ present total number of OWF criteria.

Step 6: Finally, the weight coefficients of the criteria are normalized by using following equation:

$$
\theta_{i}=\frac{w_{i}}{\operatorname{Max}\left(\tilde{w}_{i}\right)}
$$

where $\theta_{i}$ is normalized value.

Step 7: According to $\theta_{i}$, the criteria can be classified three categories such as critical, moderate and mild. These categories are presented as in the Table 2 and determined with the help of experts using the linguistic variables in Table 4.

Table 2: The categories for OWF site selection criteria.

\begin{tabular}{lc}
\hline \hline Degrees & Interval \\
\hline \hline Mild & $0.00 \leq \theta_{i}<0.700$ \\
Moderate & $0.700 \leq \theta_{i}<0.883$ \\
Critical & $0.883 \leq \theta_{i} \leq 1.00$ \\
\hline \hline
\end{tabular}

1. If $\theta_{i}<0.700$, this $i$. criterion for OWF site selection is Mild shouldn't be considered.

2. If $0.700 \leq \theta_{i}<0.883$, this $i$. criterion for OWF site selection is Moderate and should be considered. 
3. If $0.883 \leq \theta_{i} \leq 1.00$, this $i$. criterion for OWF site selection is Critical and must be considered.

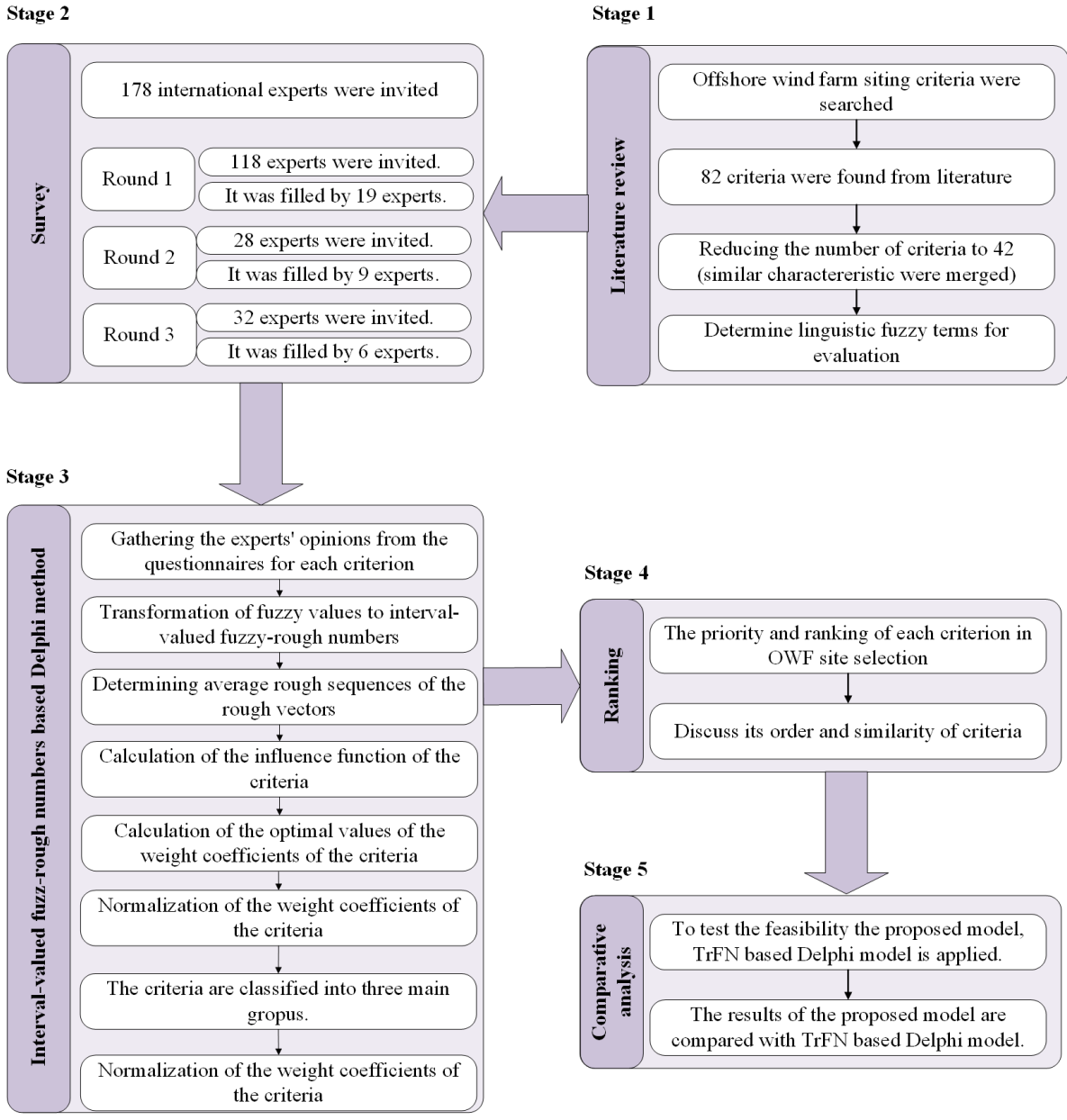

Figure 3: The schematic diagram of the Delphi-LBWA model.

\section{Problem Description}

\subsection{A Survey}

We have prepared an online questionnaire to identify the importance of various criteria for the site selection of offshore wind farms. A total of 178 international experts were invited to participate in three separate rounds from the 
academia and industry. They have in-depth knowledge, practical experiences and articles published in the field of offshore wind farm. The online survey ${ }^{1}$ was conducted by e-mail invitations using Google Drive. The majority of the participants are experts working in academia or energy companies who have publications in the field of OWF. The main characteristics of the experts are given in Table 3

Round 1:

118, 28 and 32 experts were invited for participating the online survey in the first, second and third rounds, while 19, 9 and 6 experts responded, respectively. At the end, this questionnaire was filled out by 34 different experts spread across 16 different countries. The number of experts participating the survey from each country is illusrated in Figure 4 . The top countries with the highest level of participation to the survey are United States, Greece and Netherlands and United Kingdom, respectively.

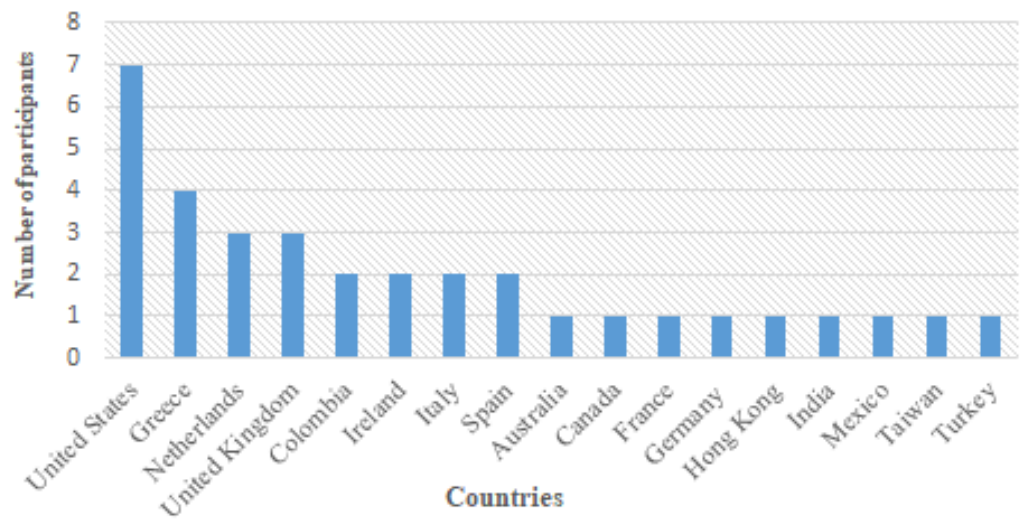

Figure 4: The number of experts participating the survey from each country.

\section{Round 2:}

28 experts were invited for participating the online survey and 9 experts responded.

\footnotetext{
${ }^{1}$ https://goo.gl/forms/JBVo7uluO9r1ykGy2
} 


\section{Round 3:}

32 experts were invited for participating the online survey and 6 experts responded.

Table 3: The main characteristics of the experts.

\begin{tabular}{lrrrr}
\hline \hline Main characteristics & Round 1 & Round 2 & Round 3 & Total \\
& $\mathrm{N}(\%)$ & $\mathrm{N}(\%)$ & $\mathrm{N}(\%)$ & \\
\hline \hline Initial number of participants & 118 & 28 & 32 & 178 \\
Number of participants filled out & $19(16.1 \%)$ & $9(28.6 \%)$ & $6(15.6 \%)$ & 34 \\
\hline Country & & & & \\
\hline Australia & $0(0 \%)$ & $1(3.57 \%)$ & $0(0 \%)$ & 1 \\
Canada & $0(0 \%)$ & $1(3.57 \%)$ & $0(0 \%)$ & 1 \\
Colombia & $0(0 \%)$ & $2(7.14 \%)$ & $0(0 \%)$ & 2 \\
France & $0(0 \%)$ & $0(0 \%)$ & $1(3.13 \%)$ & 1 \\
Germany & $1(0.85 \%)$ & $0(0 \%)$ & $0(0 \%)$ & 1 \\
Greece & $3(2.54 \%)$ & $0(0 \%)$ & $1(3.13 \%)$ & 4 \\
Hong Kong & $1(0.85 \%)$ & $0(0 \%)$ & $0(0 \%)$ & 1 \\
India & $0(0 \%)$ & $0(0 \%)$ & $1(3.13 \%)$ & 1 \\
Ireland & $2(1.69 \%)$ & $0(0 \%)$ & $0(0 \%)$ & 2 \\
Italy & $2(1.69 \%)$ & $0(0 \%)$ & $0(0 \%)$ & 2 \\
Mexico & $0(0 \%)$ & $1(3.57 \%)$ & $0(0 \%)$ & 1 \\
Netherlands & $2(1.69 \%)$ & $1(3.57 \%)$ & $0(0 \%)$ & 3 \\
Spain & $2(1.69 \%)$ & $0(0 \%)$ & $0(0 \%)$ & 2 \\
Taiwan & $0(0 \%)$ & $0(0 \%)$ & $1(3.13 \%)$ & 1 \\
Turkey & $1(0.85 \%)$ & $0(0 \%)$ & $0(0 \%)$ & 1 \\
United Kingdom & $1(0.85 \%)$ & $1(3.57 \%)$ & $1(3.13 \%)$ & 3 \\
United States & $4(3.39 \%)$ & $2(7.14 \%)$ & $1(3.13 \%)$ & 7 \\
\hline Occupation & & & & \\
\hline Practitioners & $4(3.39 \%)$ & $0(0 \%)$ & $1(3.13 \%)$ & 5 \\
Industry experts & $1(0.85 \%)$ & $0(0 \%)$ & $0(0 \%)$ & 1 \\
Other & & & & 28 \\
\hline \hline
\end{tabular}

The 28, 5 and 1 out of the 34 experts who assessed the importance of the OWF siting criteria were researchers, practitioners from energy companies and with unknown occupancy, respectively. 


\subsection{Fuzzy Linguistic Terms}

In the case of many actual decisions, the nature of the different aspects of the problem, the use of linguistic information is convenient and easy. In such cases, a common approach to modeling linguistic information is the fuzzy linguistic approach. It uses fuzzy set theory (Zadeh, 1965) to manage uncertainty and model information (Rodriguez et al., 2012).

To assess the perceived importance of OWF selection criteria, 7-scale linguistic terms that are trapezoidal were used from experts in the questionnaire. The linguistic terms corresponding fuzzy sets, and their defuzzification values are given Table 4 , respectively.

Table 4: Linguistic variables for the importance weight.

\begin{tabular}{lcc}
\hline \hline Linguistic terms & Triangular fuzzy number & Defuzzification values \\
\hline \hline Very low (VL) & $(0.0,0.0,0.1)$ & 0.017 \\
Low (L) & $(0.0,0.1,0.3)$ & 0.117 \\
Medium low (ML) & $(0.1,0.3,0.5)$ & 0.300 \\
Medium (M) & $(0.3,0.5,0.7)$ & 0.500 \\
Medium high (MH) & $(0.5,0.7,0.9)$ & 0.700 \\
High (H) & $(0.7,0.9,1.0)$ & 0.883 \\
Very high (VH) & $(0.9,1.0,1.0)$ & 0.983 \\
\hline \hline
\end{tabular}

\section{Experimental Results}

In this study, 42 different criteria for the OWF site selection are evaluated by 34 international participants that are experts in their field. The expert opinions are gathered to determine the importance of each criterion as provided in Table 5. 
Table 5: The expert opinions on the importance of the OWF site selection criteria based on linguistic terms including VL: Very Low, L: Low, ML: Medium Low, M: Medium, MH: Medium High, H: High, VH: Very High, N/A: Not Applicable, respectively.

\begin{tabular}{|c|c|c|c|c|c|c|c|c|c|c|}
\hline No & Criteria & VL & $\mathrm{L}$ & ML & M & $\mathrm{MH}$ & $\mathrm{H}$ & $\mathrm{VH}$ & $\mathrm{N} / \mathrm{A}$ & Total \\
\hline $\mathrm{C} 1$ & Wind speed & & & & & 1 & 9 & 24 & & 34 \\
\hline $\mathrm{C} 2$ & Wind directions & 1 & 6 & 2 & 9 & 6 & 5 & 5 & & 34 \\
\hline $\mathrm{C} 3$ & Wind power density & & & & 2 & 4 & 11 & 15 & 2 & 34 \\
\hline $\mathrm{C} 4$ & Wind resource availability & & & & & 2 & 11 & 19 & 2 & 34 \\
\hline C5 & Effective wind duration (in hours) & & & & 2 & 6 & 16 & 8 & 2 & 34 \\
\hline C6 & Extreme weather conditions & & & & 9 & 11 & 10 & 4 & & 34 \\
\hline $\mathrm{C} 7$ & Operation lifetime (in years) & 2 & & 2 & 7 & 6 & 10 & 4 & 3 & 34 \\
\hline $\mathrm{C} 8$ & Total project pay back period & & & 3 & 5 & 7 & 8 & 11 & & 34 \\
\hline C9 & Expected benefit to cost ratio & & & 1 & 2 & 5 & 13 & 12 & 1 & 34 \\
\hline $\mathrm{C} 10$ & Operating revenue & & 1 & 2 & 3 & 7 & 14 & 7 & & 34 \\
\hline $\mathrm{C} 11$ & Investment cost & & & & 3 & 8 & 9 & 13 & 1 & 34 \\
\hline $\mathrm{C} 12$ & Operation and maintenance costs & & & 1 & 4 & 7 & 13 & 8 & 1 & 34 \\
\hline $\mathrm{C} 13$ & Wave energy potential & 3 & 9 & 4 & 5 & 5 & 5 & 1 & 2 & 34 \\
\hline C14 & Wave height and period & 1 & 4 & 5 & 8 & 11 & 3 & 1 & 1 & 34 \\
\hline $\mathrm{C} 15$ & Tidal range and current velocity & 1 & 4 & 7 & 10 & 8 & & 3 & 1 & 34 \\
\hline $\mathrm{C} 16$ & Water depth & & 2 & & 4 & 6 & 14 & 8 & & 34 \\
\hline $\mathrm{C} 17$ & Soil conditions & & 3 & 3 & 5 & 9 & 10 & 3 & 1 & 34 \\
\hline $\mathrm{C} 18$ & Being a typhoon and/or earthquake region & & & & 8 & 13 & 8 & 5 & & 34 \\
\hline C19 & Proximity to the shore (Noise, visual impact etc.) & & & 3 & 3 & 5 & 20 & 3 & & 34 \\
\hline $\mathrm{C} 20$ & Proximity to landscape protection area & 1 & & 2 & 6 & 9 & 15 & 1 & & 34 \\
\hline $\mathrm{C} 21$ & Proximity to the facilities for wind farm construction & & 1 & 2 & 5 & 6 & 16 & 4 & & 34 \\
\hline $\mathrm{C} 22$ & Electricity transmission cable installation cost ( $\mathrm{km} / \mathrm{USD}$ million) & & 1 & & 2 & 8 & 13 & 9 & 1 & 34 \\
\hline $\mathrm{C} 23$ & Proximity to grid connections & & 1 & 1 & 1 & 3 & 20 & 8 & & 34 \\
\hline $\mathrm{C} 24$ & Proximity to the electricity demand region & & 2 & 1 & 7 & 9 & 12 & 3 & & 34 \\
\hline $\mathrm{C} 25$ & Proximity to the shipping density/congestion & & 2 & 2 & 8 & 10 & 9 & 2 & 1 & 34 \\
\hline $\mathrm{C} 26$ & Proximity to shipping lanes & & 2 & 3 & 8 & 12 & 8 & 1 & & 34 \\
\hline $\mathrm{C} 27$ & Proximity to ports/harbor & & 2 & 1 & 6 & 10 & 12 & 3 & & 34 \\
\hline $\mathrm{C} 28$ & Proximity to navigable waterways & & 2 & 3 & 9 & 9 & 9 & 1 & 1 & 34 \\
\hline $\mathrm{C} 29$ & Proximity to natural environment conservation area & & 1 & 2 & 6 & 12 & 11 & 2 & & 34 \\
\hline C30 & Effects of wind farm on marine life (marine animals) & & 1 & 1 & 6 & 10 & 10 & 5 & 1 & 34 \\
\hline $\mathrm{C} 31$ & Proximity to passage route of birds & & 2 & 4 & 7 & 7 & 11 & 3 & & 34 \\
\hline $\mathrm{C} 32$ & Proximity to contaminated/obstructed area & 1 & 3 & 6 & 8 & 5 & 7 & 1 & 3 & 34 \\
\hline C33 & Proximity to military operation area & 1 & 2 & 3 & 9 & 7 & 8 & 3 & 1 & 34 \\
\hline $\mathrm{C} 34$ & Proximity to radio and radar corridors (impact on aviation) & 2 & 3 & 4 & 7 & 9 & 5 & 2 & 2 & 34 \\
\hline C35 & Economic externalities & 1 & 3 & 3 & 7 & 9 & 7 & 2 & 2 & 34 \\
\hline C36 & Local economic benefits (employment) & 1 & 2 & 5 & 7 & 10 & 7 & 2 & & 34 \\
\hline C37 & Proximity to the hydrocarbon reserves & 5 & 5 & 5 & 8 & 5 & 2 & & 4 & 34 \\
\hline C38 & Investment incentives & & 2 & 1 & 2 & 12 & 15 & 2 & & 34 \\
\hline C39 & Production incentives & & 3 & 1 & 4 & 10 & 15 & 1 & & 34 \\
\hline $\mathrm{C} 40$ & Feed-in-tariff for offshore wind energy & & 2 & & 3 & 12 & 11 & 4 & 2 & 34 \\
\hline $\mathrm{C} 41$ & Community/local acceptance & & 1 & & 9 & 5 & 10 & 9 & & 34 \\
\hline $\mathrm{C} 42$ & Wind farm size (in terms of capacity in MW) & & & 1 & 5 & 9 & 13 & 5 & 1 & 34 \\
\hline
\end{tabular}


Using Table 4 the linguistic expressions for the importance of criteria are then converted into interval triangular fuzzy sets $a_{i}^{e}=\left(l_{i}^{e}, s_{i}^{e}, u_{i}^{e}\right)$. Using Eqs. (1)-(7) each sequence, and $l_{i}^{e}, s_{i}^{e}$ and $u_{i}^{e}$ is transformed into rough sequence. By applying Eqs. (17)-19 we obtain the average rough sequences $R N\left(\bar{l}_{i}\right)$, $R N\left(\bar{s}_{i}\right)$ and $R N\left(\bar{u}_{i}\right)$ that represents the $\overline{\bar{a}}_{i}=\left[\left(\bar{l}_{i}^{L}, \bar{l}_{i}^{U}\right),\left(\bar{s}_{i}^{L}, \bar{s}_{i}^{U}\right),\left(\bar{u}_{i}^{L}, \bar{u}_{i}^{U}\right)\right]$ for each criterion, as given in Table 6 .

Then, the IVFRN values capturing aggregated expert opinion are defuzzified by using Eq. (20). The defuzzification values for each criterion is given in the fourth column of Table 6 ,

The criteria weights are calculated by Eqs. 21-23) as given in sixth column of Table 6. Subsequently, the weight values are normalized using Eq. 24) as given in the seventh column of the same table. This is also the normalised value of each criterion $\left(\theta_{i}\right)$. Then, the criteria are classified according to the degree of importance consisting of critical, moderate and mildin the last column of this table. 
Table 6: Overall value of offshore wind farm site selection criteria.

\begin{tabular}{|c|c|c|c|c|c|c|c|c|}
\hline No & Criteria & Aggregated IVFRN & Defuzzy & $\max \left(a_{i}\right)-a_{i}$ & $w_{i}$ & Score value $\left(\theta_{i}\right)$ & Rank & Degrees \\
\hline $\mathrm{C} 1$ & Wind speed & {$[(0.81,0.88),(0.94,0.99),(0.99,1)]$} & 1.795 & 0.000 & 0.029 & 1.000 & 1 & Critical \\
\hline $\mathrm{C} 2$ & Wind directions & {$[(0.4,0.62),(0.62,0.79),(0.79,0.89)]$} & 1.133 & 0.662 & 0.022 & 0.751 & 34 & Moderate \\
\hline C3 & Wind power density & {$[(0.7,0.83),(0.85,0.96),(0.96,0.99)]$} & 1.640 & 0.155 & 0.027 & 0.928 & 3 & Critical \\
\hline $\mathrm{C} 4$ & Wind resource availability & {$[(0.74,0.86),(0.87,0.97),(0.97,0.99)]$} & 1.687 & 0.108 & 0.028 & 0.949 & 2 & Critical \\
\hline $\mathrm{C} 5$ & Effective wind duration (in hours) & {$[(0.63,0.77),(0.79,0.92),(0.92,0.98)]$} & 1.520 & 0.275 & 0.026 & 0.879 & 7 & Moderate \\
\hline $\mathrm{C} 6$ & Extreme weather conditions & {$[(0.54,0.68),(0.72,0.85),(0.86,0.96)]$} & 1.348 & 0.447 & 0.024 & 0.817 & 20 & Moderate \\
\hline $\mathrm{C} 7$ & Operation lifetime (in years) & {$[(0.45,0.66),(0.66,0.83),(0.83,0.93)]$} & 1.235 & 0.559 & 0.023 & 0.781 & 29 & Moderate \\
\hline $\mathrm{C} 8$ & Total project pay back period & {$[(0.59,0.78),(0.78,0.92),(0.92,0.97)]$} & 1.484 & 0.311 & 0.025 & 0.866 & 11 & Moderate \\
\hline C9 & Expected benefit to cost ratio & {$[(0.66,0.81),(0.81,0.95),(0.95,0.99)]$} & 1.580 & 0.215 & 0.026 & 0.903 & 4 & Critical \\
\hline $\mathrm{C} 10$ & Operating revenue & {$[(0.59,0.75),(0.76,0.91),(0.91,0.98)]$} & 1.470 & 0.325 & 0.025 & 0.860 & 13 & Moderate \\
\hline C11 & Investment cost & {$[(0.65,0.81),(0.81,0.94),(0.94,0.98)]$} & 1.564 & 0.231 & 0.026 & 0.896 & 6 & Critical \\
\hline C12 & Operation and maintenance costs & {$[(0.6,0.77),(0.77,0.92),(0.92,0.98)]$} & 1.485 & 0.310 & 0.025 & 0.866 & 10 & Moderate \\
\hline C13 & Wave energy potential & {$[(0.25,0.45),(0.45,0.64),(0.64,0.79)]$} & 0.820 & 0.975 & 0.020 & 0.672 & 41 & Mild \\
\hline C14 & Wave height and period & {$[(0.33,0.5),(0.5,0.69),(0.69,0.86)]$} & 0.945 & 0.849 & 0.021 & 0.702 & 39 & Moderate \\
\hline C15 & Tidal range and current velocity & {$[(0.3,0.48),(0.48,0.66),(0.66,0.81)]$} & 0.881 & 0.914 & 0.020 & 0.686 & 40 & Mild \\
\hline C16 & Water depth & {$[(0.61,0.76),(0.77,0.92),(0.92,0.98)]$} & 1.492 & 0.303 & 0.025 & 0.868 & 9 & Moderate \\
\hline C17 & Soil conditions & {$[(0.46,0.65),(0.65,0.83),(0.83,0.94)]$} & 1.238 & 0.557 & 0.023 & 0.782 & 28 & Moderate \\
\hline C18 & Being a typhoon and/or earthquake region & {$[(0.54,0.69),(0.72,0.85),(0.87,0.95)]$} & 1.354 & 0.441 & 0.024 & 0.819 & 19 & Moderate \\
\hline C19 & Proximity to the shore (Noise, visual impact etc.) & {$[(0.6,0.72),(0.79,0.9),(0.92,0.99)]$} & 1.483 & 0.312 & 0.025 & 0.865 & 12 & Moderate \\
\hline $\mathrm{C} 20$ & Proximity to landscape protection area & {$[(0.51,0.05),(0.7,0.85),(0.85,0.96)]$} & 1.314 & 0.481 & 0.024 & 0.806 & 23 & Moderate \\
\hline $\mathrm{C} 21$ & Proximity to the facilities for wind farm construction & {$[(0.56,0.71),(0.74,0.89),(0.89,0.97)]$} & 1.408 & 0.387 & 0.025 & 0.838 & 16 & Moderate \\
\hline $\mathrm{C} 22$ & Electricity transmission cable installation cost ( $\mathrm{km} / \mathrm{USD}$ million) & {$[(0.62,0.78),(0.78,0.92),(0.92,0.98)]$} & 1.514 & 0.281 & 0.026 & 0.877 & 8 & Moderate \\
\hline $\mathrm{C} 23$ & Proximity to grid connections & {$[(0.66,0.78),(0.83,0.94),(0.94,0.99)]$} & 1.576 & 0.219 & 0.026 & 0.901 & 5 & Critical \\
\hline $\mathrm{C} 24$ & Proximity to the electricity demand region & {$[(0.51,0.67),(0.69,0.85),(0.85,0.95)]$} & 1.312 & 0.483 & 0.024 & 0.806 & 24 & Moderate \\
\hline $\mathrm{C} 25$ & Proximity to the shipping density/congestion & {$[(0.45,0.62),(0.63,0.81),(0.81,0.93)]$} & 1.195 & 0.599 & 0.023 & 0.769 & 30 & Moderate \\
\hline $\mathrm{C} 26$ & Proximity to shipping lanes & {$[(0.44,0.59),(0.63,0.78),(0.81,0.92)]$} & 1.176 & 0.619 & 0.022 & 0.764 & 31 & Moderate \\
\hline $\mathrm{C} 27$ & Proximity to ports/harbor & {$[(0.49,0.65),(0.67,0.84),(0.84,0.95)]$} & 1.275 & 0.519 & 0.023 & 0.794 & 26 & Moderate \\
\hline $\mathrm{C} 28$ & Proximity to navigable waterways & {$[(0.42,0.59),(0.6,0.78),(0.78,0.91)]$} & 1.140 & 0.655 & 0.022 & 0.753 & 33 & Moderate \\
\hline $\mathrm{C} 29$ & Proximity to natural environment conservation area & {$[(0.52,0.66),(0.71,0.84),(0.87,0.96)]$} & 1.327 & 0.468 & 0.024 & 0.810 & 22 & Moderate \\
\hline C30 & Effects of wind farm on marine life (marine animals) & {$[(0.53,0.7),(0.7,0.86),(0.86,0.96)]$} & 1.343 & 0.452 & 0.024 & 0.816 & 21 & Moderate \\
\hline C31 & Proximity to passage route of birds & {$[(0.47,0.65),(0.65,0.83),(0.83,0.94)]$} & 1.249 & 0.546 & 0.023 & 0.786 & 27 & Moderate \\
\hline C32 & Proximity to contaminated/obstructed area & {$[(0.33,0.53),(0.53,0.72),(0.72,0.86)]$} & 0.982 & 0.813 & 0.021 & 0.711 & 38 & Moderate \\
\hline C33 & Proximity to military operation area & {$[(0.42,0.62),(0.62,0.8),(0.8,0.91)]$} & 1.167 & 0.628 & 0.022 & 0.761 & 32 & Moderate \\
\hline $\mathrm{C} 34$ & Proximity to radio and radar corridors (impact on aviation) & {$[(0.35,0.55),(0.55,0.74),(0.74,0.87)]$} & 1.025 & 0.770 & 0.021 & 0.722 & 37 & Moderate \\
\hline C35 & Economic externalities & {$[(0.39,0.58),(0.58,0.77),(0.77,0.9)]$} & 1.098 & 0.696 & 0.022 & 0.742 & 36 & Moderate \\
\hline C36 & Local economic benefits (employment) & {$[(0.41,0.6),(0.6,0.78),(0.78,0.91)]$} & 1.128 & 0.666 & 0.022 & 0.750 & 35 & Moderate \\
\hline C37 & Proximity to the hydrocarbon reserves & {$[(0.19,0.35),(0.35,0.53),(0.53,0.72)]$} & 0.646 & 1.148 & 0.019 & 0.635 & 42 & Mild \\
\hline C38 & Investment incentives & {$[(0.56,0.68),(0.75,0.87),(0.89,0.97)]$} & 1.405 & 0.390 & 0.025 & 0.837 & 17 & Moderate \\
\hline C39 & Production incentives & {$[(0.51,0.65),(0.69,0.85),(0.85,0.96)]$} & 1.308 & 0.486 & 0.024 & 0.804 & 25 & Moderate \\
\hline C40 & Feed-in-tariff for offshore wind energy & {$[(0.54,0.69),(0.71,0.87),(0.87,0.96)]$} & 1.365 & 0.430 & 0.024 & 0.823 & 18 & Moderate \\
\hline C41 & Community/local acceptance & {$[(0.58,0.75),(0.75,0.9),(0.9,0.96)]$} & 1.440 & 0.355 & 0.025 & 0.849 & 14 & Moderate \\
\hline C42 & Wind farm size (in terms of capacity in MW) & {$[(0.56,0.72),(0.74,0.89),(0.89,0.97)]$} & 1.411 & 0.384 & 0.025 & 0.839 & 15 & Moderate \\
\hline
\end{tabular}

The aggregated IVFRN values of the criteria collected from all experts are depicted as box-plots in Figure 5 . The box-plots display the symmetry and deviations in the data. According to the box-plots, the importance level of the $C 13, C 15$ and $C 37$ criteria are the lowest and also their deviation of differences of opinion among experts are high. Moreover, the importance level of the $C 1$, $C 3$ and $C 4$ criteria are the highest with relatively low deviation in the differences of opinion. 


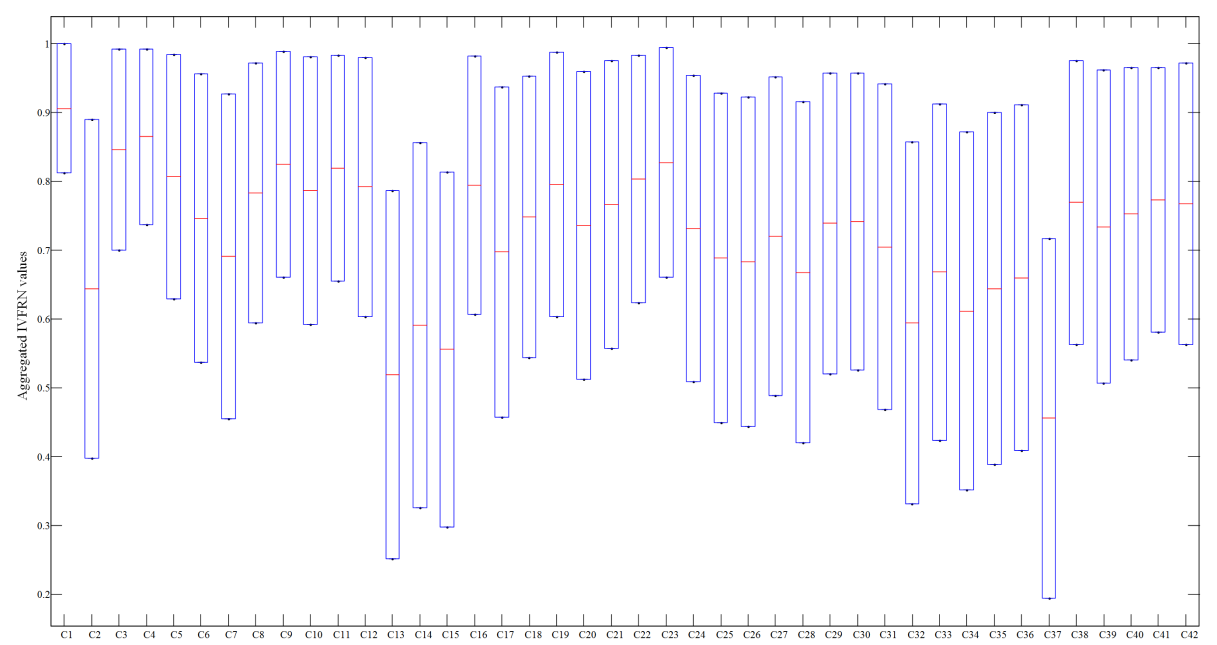

Figure 5: The aggregated IVFRN values of the weight coefficients of the criteria.

\subsection{Comparison of IVRN Results}

To test the feasibility and validty of the proposed interval-valued fuzzyrough numbers based Delphi model, it is compared with the traditional type-1 fuzzy number (TrFN) based Delphi model that proposed by Zadeh (1965). From Figures 6 and 8 , it can be noted that $C_{1}, C_{4}$ and $C_{3}$ are the most crucial criteria, respectively. Table A.1 presents the results of TrFN based Delphi model.

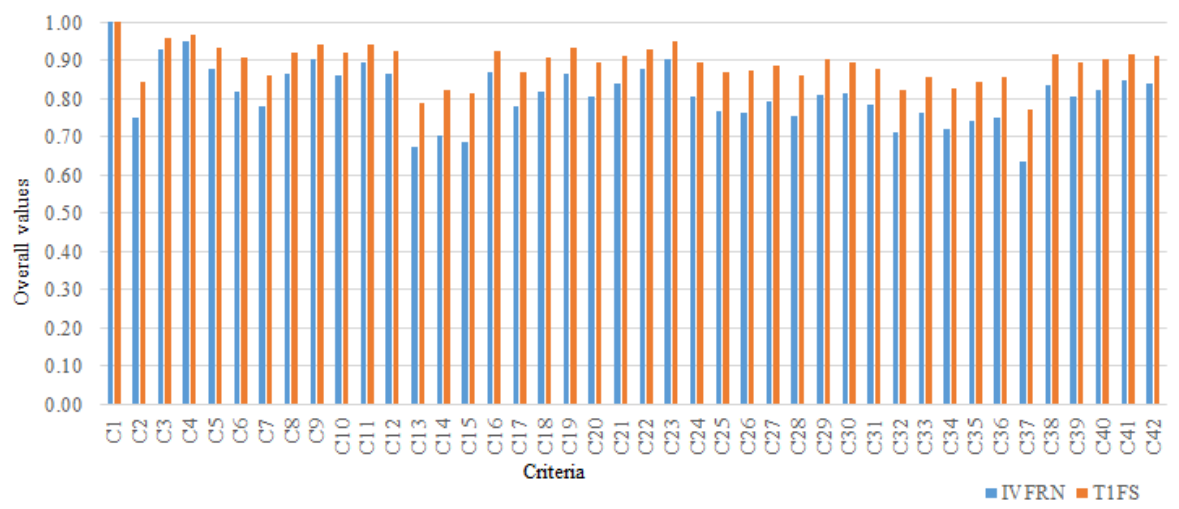

Figure 6: Comparison results of IVRN and type 1 fuzzy sets based on overall values.

According to the results of IVFRN and TrFN based Delphi model, we ob- 
serve almost no similarities between any of the ranking of criteria. Such small inconsistency in the ranking was expected because there were different mathematical models. However, the top three criteria ( $C 1, C 4$ and $C 3$, respectively) and the lowest seven criteria $(C 35, C 34, C 32, C 14, C 15, C 13$, and $C 37$, respectively) have the same ranking. Figure 7 shows the number of importance of criteria between IVFRN and TrFN.

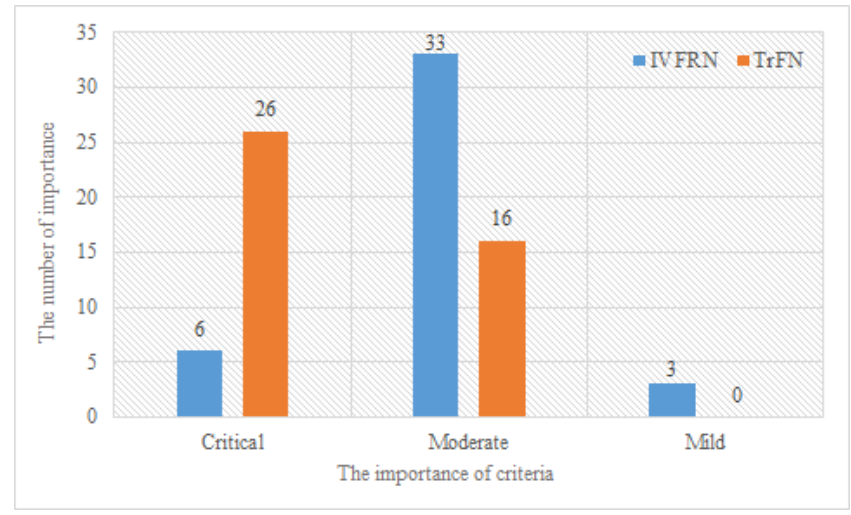

Figure 7: Comparison of the number of importance between IVFRN and TrFN.

The ranking results and reliability of the proposed approach are verified by the experts. They have confirmed that our proposed IVFRN based Delphi model presents more meaningful results. 


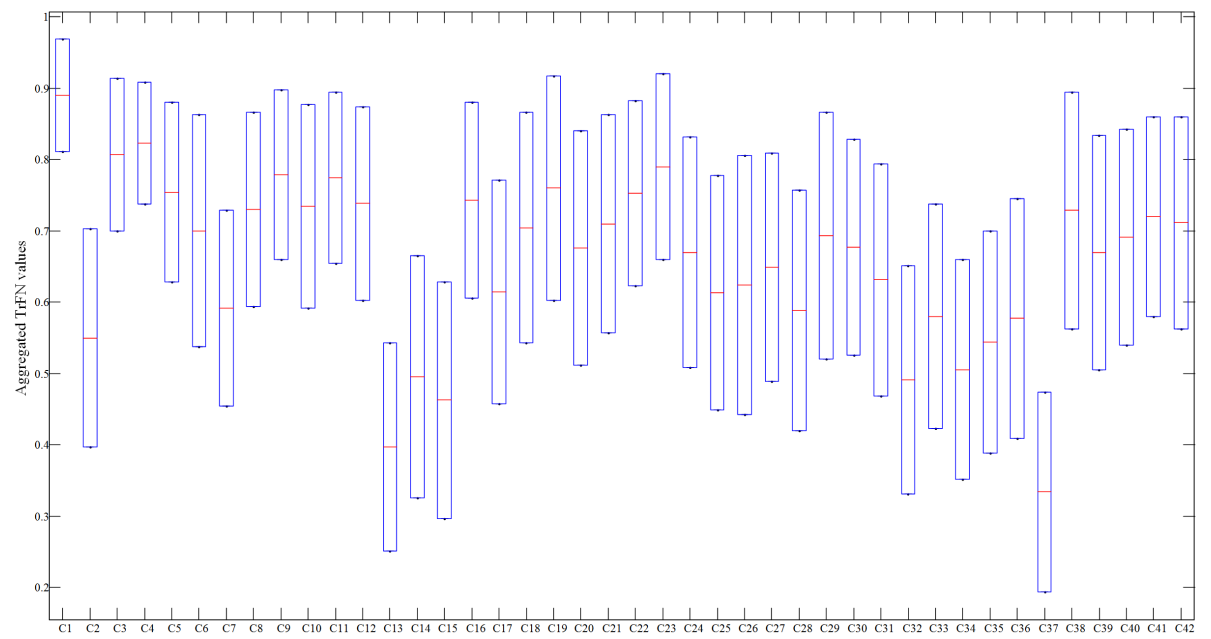

Figure 8: The aggregated $\operatorname{TrFN}$ values of the weight coefficients of the criteria.

\subsection{Comparison of Grouping Results}

We run the model separately to see the difference between response of the practitioners and researchers. The difference in values are presented by overlapping charts in Fig. 9. As can be seen this from this figure, the criteria overlap in terms of groups. There are slightly difference between some criteria. We consider this slightly difference occurs due to the focus of each group. Practitioners tend to add considerable weight to most criteria (they analyze all criteria at once) while field experts focus more on the main problems that show up in real situations (since they know that some of the criteria, or combinations of criteria do not occur in most situations). 


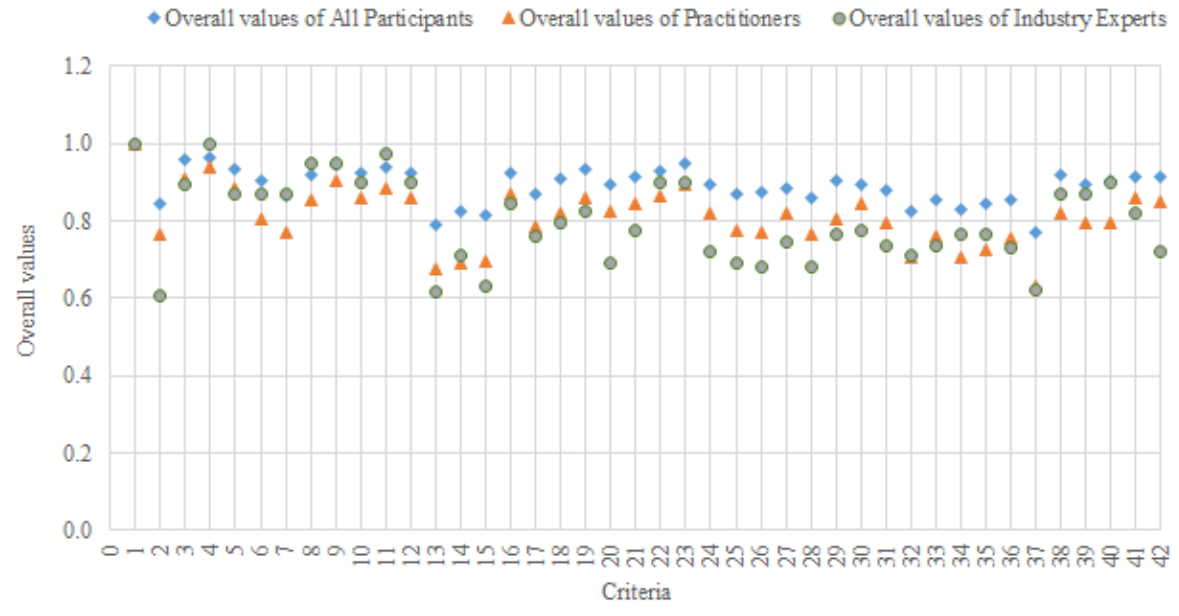

Figure 9: The overlapping chart of data series for two groups.

The fuzzy weight coefficients of criteria evaluated by practitioners and industry experts are also illustrated in Fig. 10. 


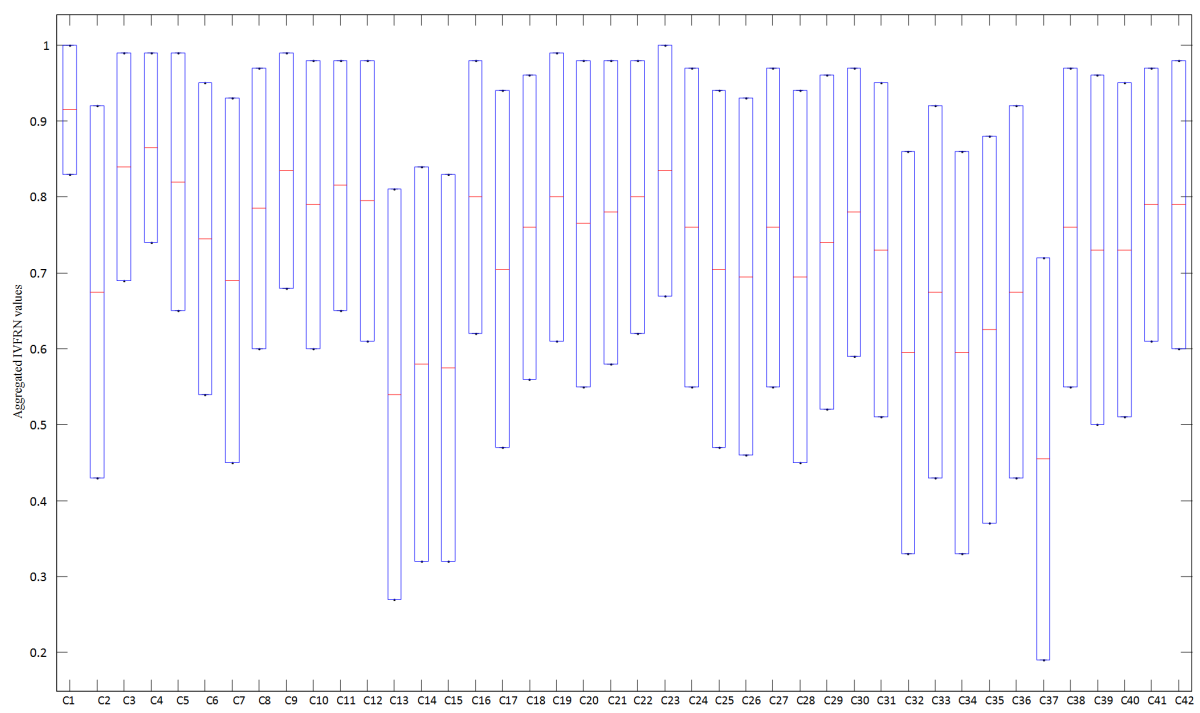

(a) Practitioners

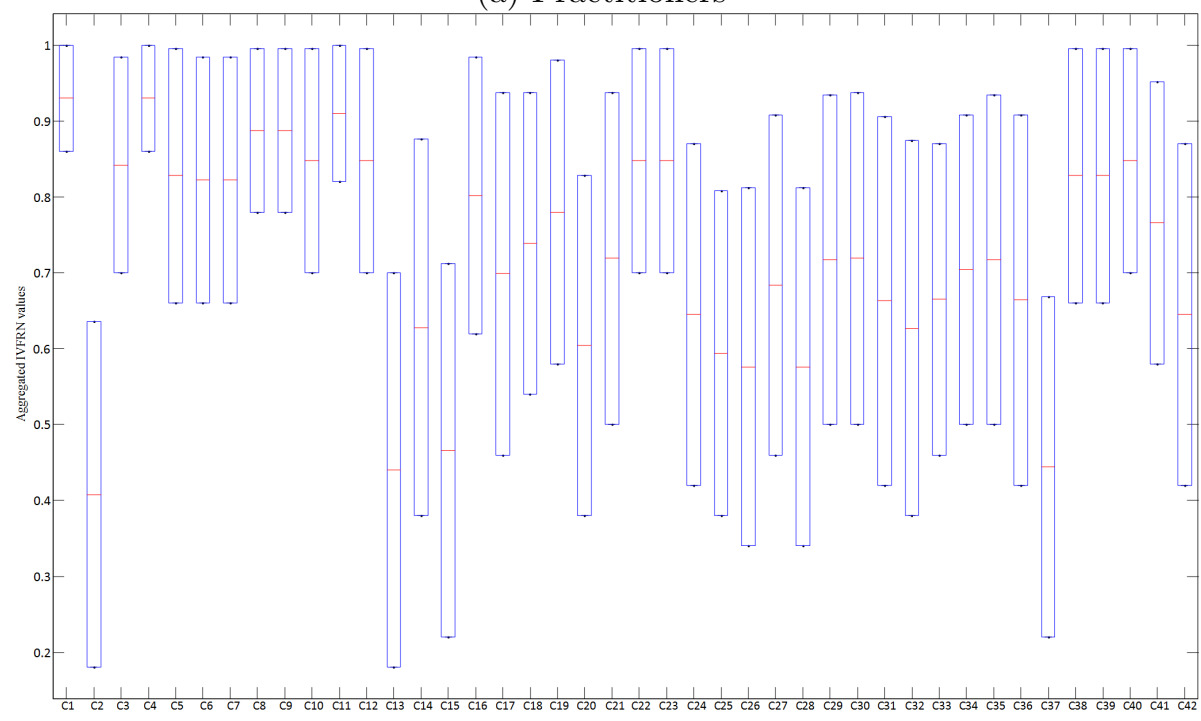

(b) Industry Experts

Figure 10: The fuzzy weight coefficients of criteria evaluated by practitioners and industry experts.

Hierarchical clustering is performed to find the similarity among the participants. The Wards method that says that the distance between two clusters 
is used for similarity. The hierarchical relationship among the participants is illustrated by dendrogram as shown in Fig. 12 . According to this dendrogram, the most similarity participant $\{25$ and 29$\},\{2$ and 19$\},\{16$ and 30$\},\{7$ and $13\},\{1$ and 6$\},\{9$ and 15$\}$ ending with participant $\{1$ and 3$\}$, respectively.

We performed statistical analysis compare the means between two groups in terms of each criterion on SPSS. Independent samples t-test was used for the analysis of two groups. It compares the means of two independent groups in order to determine whether there is statistical evidence. Firstly, we could test the stability of the data by using normality. Each group of histogram and probability are shown in Fig. 11. When we check these plots, the groups are normally distributed. According to t-test results, there is no relationship between the two groups in terms of criteria. There is only a significant difference in one criterion $(\mathrm{C} 42)$ in terms of practitioner and industry expert. 


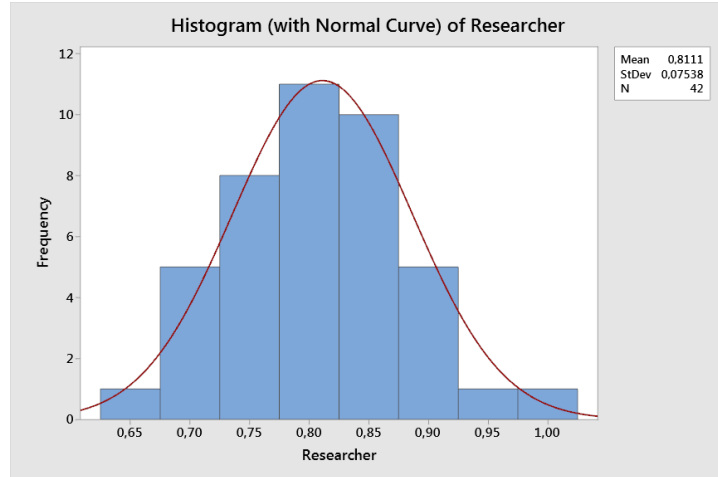

(a) histogram of practitioners

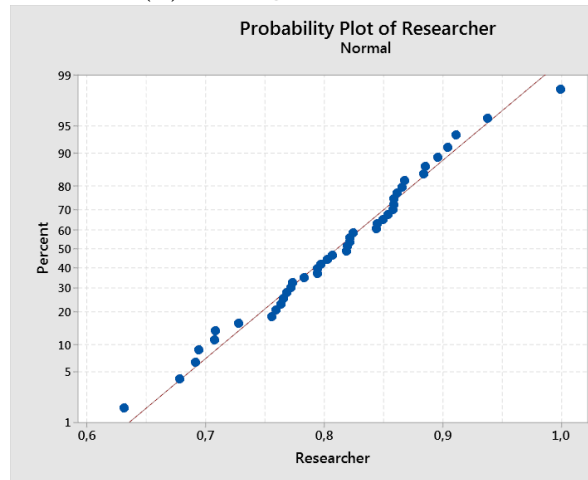

(c) probability of practitioners

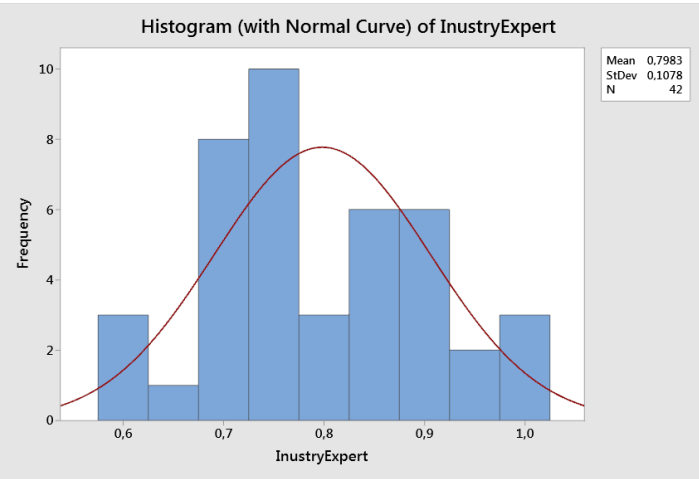

(b) histogram of industry expert

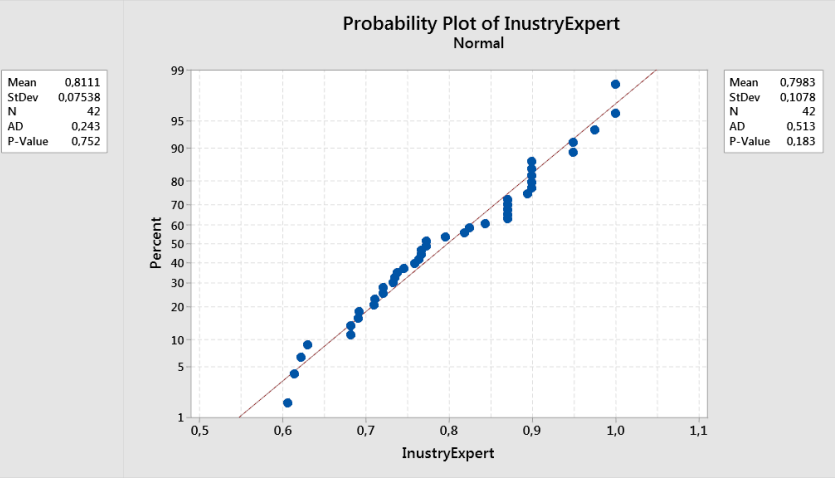

(d) probability of industry expert

Figure 11: The histograms and probability of two groups (practitioners and industry experts). 


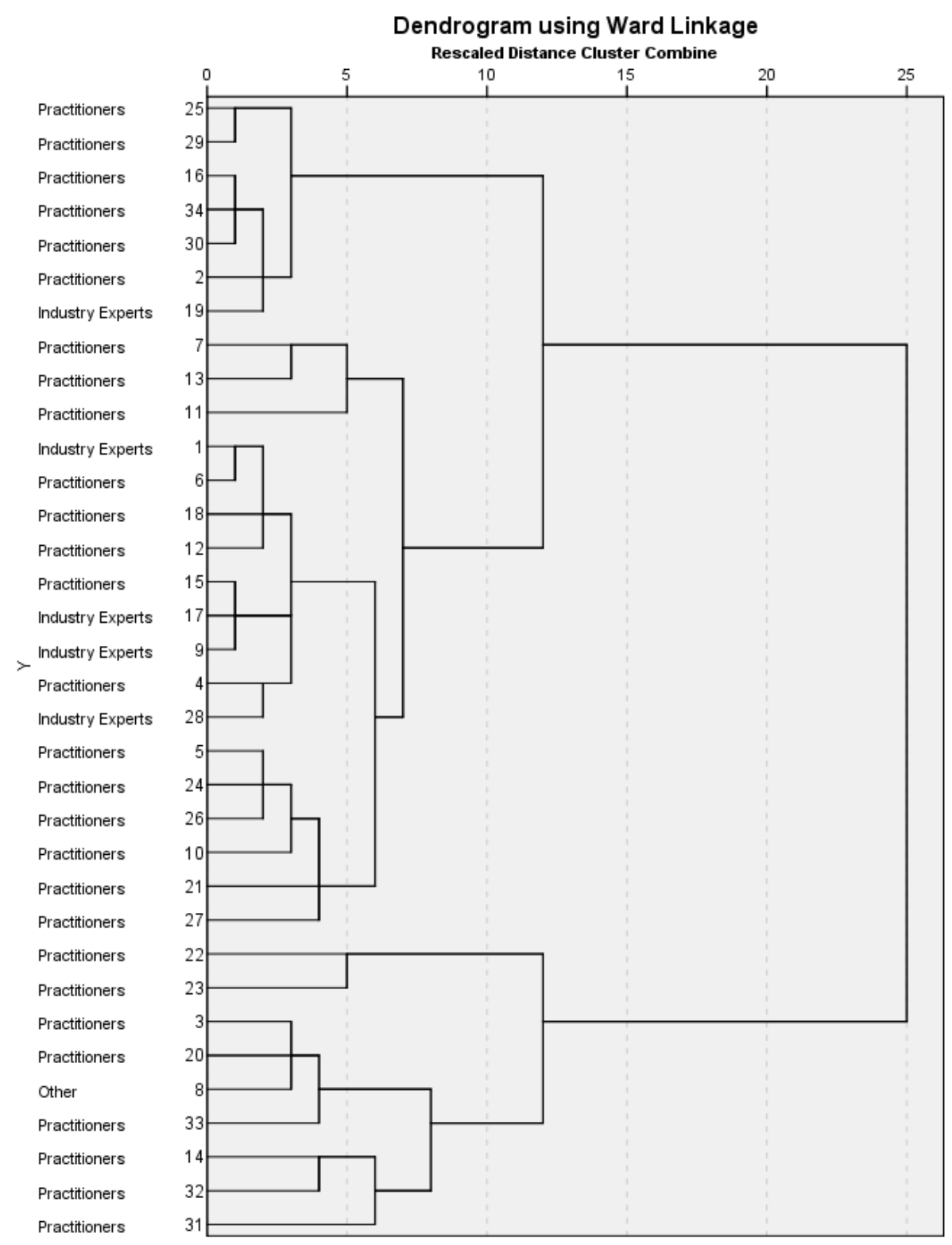

Figure 12: The hierarchical relationship of the response of participants. 


\section{Results and discussion}

To determine level of the importance of OWF siting criteria, the experts have evaluated 42 criteria in interval-valued fuzzy-rough numbers based Delphi rounds. We were particularly interested in the consensus (critical) and dissensus (uncritical) of experts opinions and their feedback about criteria. These criteria are ranked by priorities and preferences of relevant experts from the highest score to the lowest score using Table 6. According this table, the most important siting criteria is C1 (Wind speed), C4 (Wind resource availability), C3 (Wind power density), C9 (Expected benefit to cost ratio), C23 (proximity to grid connections), C11 (Investment cost), C5 (Effective wind duration), ending with C37 (Proximity to the hydrocarbon reserves), respectively.

As expected, the criteria that scored high in the ranking are the ones that are directly tied to the financial side of the offshore wind farm (both benefits and costs). The most important factors is the wind speed, noting that the wind turbines need a certain wind speed range to generate electricity. To have a wind farm with a good capacity factor, the wind availability, density and duration are also an important factors - although the capacity factor is more of an economic decision related to the investment and operational costs (over the lifespan of the wind farm the weather fluctuations will average out). The following criteria in the ranking are linked to the investment, technical challenges, operational costs and the social acceptance - somewhat guaranteeing a full lifespan for the wind farm.

Some of the 42 criteria obtained from published studies in the literature for OWF site selection are considered as unnecessary by some of the experts. These criteria are defined as not applicable by the experts for OWF site selection. For example, C37 Criterion (proximity to the hydrocarbon reserves) is defined as not applicable criterion by four experts for OWF site selection according to Table6 - a wind farm will only slightly interfere with the operation of the hydrocarbon reserve areas and the other way around. Arguably, the lifespan of the farm isn't an important criteria, wind farms having a relatively fast payback period. 
Additionally a wind farm installed in an area that is contaminated or obstructed would only bring additional costs during the construction phase.

According to the experts, other important criteria should be considered when a new offshore wind farm is planned. Some of them would be: local legislation and procedures (e.g. authorisation process, permits etc.), additional costs if HVDC (high-voltage direct current) connections are used for wind farms that are located farther from shore, correlation with power demand, tourism impact, fishing grounds proximity, wildlife migration passage proximity, submerged cultural resources proximity and feasibility of future expansions in the area.

Some of the 42 criteria presented in this paper could be considered as overlapping or directly linked. For example, the pay back period among others considers all the economic oriented facts such as wind speed, incentives, operational and maintenance costs etc. However, for this study it was decided to detail the criteria at a finer scale in order to have a better picture of the factors that should be considered when a new offshore wind farm is planned.

\section{Conclusion}

Offshore wind farm (OWF) siting criteria should always be taken into account by energy companies, because criteria can have very positive or very detrimental and negative effects on the overall performance of OWF site. The selecting the most suitable sites for OWF is of high importance in terms of technical, environmental, economic and social criteria.

In the context of achieving more renewable energy integration, the proposed study is mainly intended to assist the decision and policy makers in ranking the potential of offshore wind sites - taking into consideration the importance of a comprehensive list of technical and non technical criteria.

This study adopted a interval-valued fuzzy-rough numbers (IVFRN) based Delphi method that integrates expert's knowledge in identifying and prioritizing OWF site selection criteria. The fuzzy set theory is used to address uncertainty and vagueness of judgments and the group decision-making process is applied 
by the Delphi method. The findings of this study is as follows: (1) Identify the importance of various criteria for the site selection of offshore wind farms (2) Determined priorities and preferences of relevant experts for siting criteria (3) This study provides valuable expert feedback and the results show that wind speed for siting ranks the highest among the 42 identified criteria (4) It has been discovered that some criteria are uncritical for OWF site selection (5) IVFRN based Delphi method is proposed to reflect uncertainty of inaccurate and vague information, and (5) Finally, comparative analysis are presents to validate the proposed model. The results of the proposed model are compared with TrFN based Delphi model.

The advantages of IVFRN are numerous. IVFRN uses only the internal knowledge to compute the limit values of the attributes for a decision. This way, the subjectivity and assumptions for defining the limit values of traditional fuzzy sets are eliminated which would affect the attribute values and so the final choice of alternatives. IVFRN exploits the structure of the given data, exclusively and utilises the uncertainties that already exist in the data, improving the objectivity of the decision process. Another advantage of this approach is its suitability for the use in sets characterized by small amount of data, and for which traditional statistical models are not appropriate. Since this Delphi - LBWA approach based on IVFRN has not been considered so far in the literature, future research should be directed towards the use of Delphi - LBWA model in traditional multicriteria models for determining the weight coefficients of criteria and evaluation. Further integration of the interval-valued fuzzy-rough approach in traditional MCDM models would allow the exploitation of the ambiguities and subjectivity that exist in the process of decision making.

In addition, due to insufficient experts and other criteria, some prejudices of the survey results may still exist. However, the results of this research are feasible and practical and can be applied in further investigation as reference for OWF site selection. The proposed interval IVFRN based Delphi method can easily be extended to assess criteria for other site selection problems or even a totally different multi-criteria decision making problem. 


\section{References}

Argin M, Yerci V, Erdogan N, Kucuksari S, Cali U. Exploring the offshore wind energy potential of turkey based on multi-criteria site selection. Energy Strategy Reviews 2019;23:33-46.

Bailey H, Brookes KL, Thompson PM. Assessing environmental impacts of offshore wind farms: lessons learned and recommendations for the future. Aquatic biosystems 2014;10(1):8.

Bouzon M, Govindan K, Rodriguez CMT, Campos LM. Identification and analysis of reverse logistics barriers using fuzzy delphi method and ahp. Resources, Conservation and Recycling 2016;108:182-97.

Breton SP, Moe G. Status, plans and technologies for offshore wind turbines in europe and north america. Renewable Energy 2009;34(3):646-54.

Cali U, Erdogan N, Kucuksari S, Argin M. Techno-economic analysis of high potential offshore wind farm locations in turkey. Energy strategy reviews $2018 ; 22: 325-36$.

Chang PL, Hsu CW, Chang PC. Fuzzy delphi method for evaluating hydrogen production technologies. International Journal of Hydrogen Energy 2011;36(21):14172-9.

Chang PT, Huang LC, Lin HJ. The fuzzy delphi method via fuzzy statistics and membership function fitting and an application to the human resources. Fuzzy Sets and Systems 2000;112(3):511-20.

Chaouachi A, Covrig CF, Ardelean M. Multi-criteria selection of offshore wind farms: Case study for the baltic states. Energy Policy 2017;103:179-92.

Chen CW, Wang JH, Wang JC, Shen ZH. Developing indicators for sustainable campuses in taiwan using fuzzy delphi method and analytic hierarchy process. Journal of cleaner production 2018;193:661-71. 
Dalkey N, Helmer O. An experimental application of the delphi method to the use of experts. Management science 1963;9(3):458-67.

Del Jesus F, Menéndez M, Guanche R, Losada IJ. A wind chart to characterize potential offshore wind energy sites. Computers \& Geosciences 2014;71:62-72.

Fetanat A, Khorasaninejad E. A novel hybrid mcdm approach for offshore wind farm site selection: A case study of iran. Ocean \& Coastal Management 2015;109:17-28.

Gaudiosi G. Offshore wind energy prospects. Renewable Energy 1999;16(14):828-34.

Habibi A, Jahantigh FF, Sarafrazi A. Fuzzy delphi technique for forecasting and screening items. Asian Journal of Research in Business Economics and Management 2015;5(2):130-43.

Ho LW, Lie TT, Leong PT, Clear T. Developing offshore wind farm siting criteria by using an international delphi method. Energy Policy 2018;113:5367.

Hsueh SL. Assessing the effectiveness of community-promoted environmental protection policy by using a delphi-fuzzy method: A case study on solar power and plain afforestation in taiwan. Renewable and Sustainable Energy Reviews 2015;49:1286-95.

Ishikawa A, Amagasa M, Shiga T, Tomizawa G, Tatsuta R, Mieno H. The maxmin delphi method and fuzzy delphi method via fuzzy integration. Fuzzy sets and systems 1993;55(3):241-53.

Janković A, Popović M. Methods for assigning weights to decision makers in group ahp decision-making. Decision Making: Applications in Management and Engineering 2019;2(1):147-65.

Kempton W, Firestone J, Lilley J, Rouleau T, Whitaker P. The offshore wind power debate: views from cape cod. Coastal management 2005;33(2):119-49. 
Kim CK, Jang S, Kim TY. Site selection for offshore wind farms in the southwest coast of south korea. Renewable energy 2018;120:151-62.

Kim JY, Oh KY, Kang KS, Lee JS. Site selection of offshore wind farms around the korean peninsula through economic evaluation. Renewable Energy 2013;54:189-95.

Kim T, Park JI, Maeng J. Offshore wind farm site selection study around jeju island, south korea. Renewable energy 2016;94:619-28.

Kurian V, Narayanan S, Ganapathy C. Towers for offshore wind turbines. In: AIP Conference Proceedings. AIP; volume 1225; 2010. p. 475-87.

Ladenburg J, Dubgaard A. Willingness to pay for reduced visual disamenities from offshore wind farms in denmark. Energy Policy 2007;35(8):4059-71.

Lynch K, Murphy J, Serri L, Airoldi D. Site selection methodology for combined wind and ocean energy technologies in europe. In: Proceedings of the 4th International Conference on Ocean Energy, Dublin, Ireland. volume 17; 2012.

Ma Z, Shao C, Ma S, Ye Z. Constructing road safety performance indicators using fuzzy delphi method and grey delphi method. Expert Systems with Applications 2011;38(3):1509-14.

Markard J, Petersen R. The offshore trend: Structural changes in the wind power sector. Energy Policy 2009;37(9):3545-56.

Mekonnen AD, Gorsevski PV. A web-based participatory gis (pgis) for offshore wind farm suitability within lake erie, ohio. Renewable and Sustainable Energy Reviews 2015;41:162-77.

Mikaeil R, Ozcelik Y, Yousefi R, Ataei M, Hosseini SM. Ranking the sawability of ornamental stone using fuzzy delphi and multi-criteria decision-making techniques. International Journal of Rock Mechanics and Mining Sciences $2013 ; 58: 118-26$. 
Möller B. Continuous spatial modelling to analyse planning and economic consequences of offshore wind energy. Energy Policy 2011;39(2):511-7.

Mostafaeipour A. Feasibility study of offshore wind turbine installation in iran compared with the world. Renewable and Sustainable Energy Reviews 2010;14(7):1722-43.

Nordman EE, VanderMolen J, Gajewski B, Ferguson A. Great lakes, great debates: Facilitating public engagement on offshore wind energy using the delphi inquiry approach. 2013. .

Ocampo L, Ebisa JA, Ombe J, Escoto MG. Sustainable ecotourism indicators with fuzzy delphi method-a philippine perspective. Ecological indicators 2018;93:874-88.

Pamučar D, Petrović I, Ćirović G. Modification of the best-worst and mabac methods: A novel approach based on interval-valued fuzzy-rough numbers. Expert systems with applications 2018;91:89-106.

Pamučar DS, Ćirović G, Božanić D. Application of interval valued fuzzy-rough numbers in multi-criteria decision making: The ivfrn-mairca model. Yugoslav Journal of Operations Research 2019;29(2):221-47.

Pawlak Z. Rough sets. International journal of computer \& information sciences 1982;11(5):341-56.

Pawlak Z. Rough sets: Theoretical aspects of reasoning about data. volume 9 . Springer Science \& Business Media, 2012.

Pham TY, Ma HM, Yeo GT. Application of fuzzy delphi topsis to locate logistics centers in vietnam: The logisticians perspective. The Asian Journal of Shipping and Logistics 2017;33(4):211-9.

Punt MJ, Groeneveld RA, Van Ierland EC, Stel JH. Spatial planning of offshore wind farms: A windfall to marine environmental protection? Ecological Economics 2009;69(1):93-103. 
Rodriguez RM, Martinez L, Herrera F. Hesitant fuzzy linguistic term sets for decision making. IEEE Transactions on fuzzy systems 2012;20(1):109-19.

Roy J, Pamučar D, Kar S. Evaluation and selection of third party logistics provider under sustainability perspectives: an interval valued fuzzy-rough approach. Annals of Operations Research 2019;:1-46.

Schillings C, Wanderer T, Cameron L, van der Wal JT, Jacquemin J, Veum K. A decision support system for assessing offshore wind energy potential in the north sea. Energy Policy 2012;49:541-51.

Song W, Ming X, Wu Z, Zhu B. A rough topsis approach for failure mode and effects analysis in uncertain environments. Quality and Reliability Engineering International 2014;30(4):473-86.

Stanković M, Gladović P, Popović V. Determining the importance of the criteria of traffic accessibility using fuzzy ahp and rough ahp method. Decision Making: Applications in Management and Engineering 2019;2(1):86-104.

Vafadarnikjoo A, Mishra N, Govindan K, Chalvatzis K. Assessment of consumers' motivations to purchase a remanufactured product by applying fuzzy delphi method and single valued neutrosophic sets. Journal of cleaner production 2018;196:230-44.

Vagiona D, Karanikolas N. A multicriteria approach to evaluate offshore wind farms siting in greece. Global NEST Journal 2012;14(2):235-43.

Vasileiou M, Loukogeorgaki E, Vagiona DG. Gis-based multi-criteria decision analysis for site selection of hybrid offshore wind and wave energy systems in greece. Renewable and sustainable energy reviews 2017;73:745-57.

Wu Y, Zhang J, Yuan J, Geng S, Zhang H. Study of decision framework of offshore wind power station site selection based on electre-iii under intuitionistic fuzzy environment: A case of china. Energy Conversion and Management 2016;113:66-81. 
Zadeh LA. Fuzzy sets. Information and control 1965;8(3):338-53.

Zhai LY, Khoo LP, Zhong ZW. Towards a qfd-based expert system: A novel extension to fuzzy qfd methodology using rough set theory. Expert Systems with Applications 2010;37(12):8888-96.

Žižović M, Pamucar D. New model for determining criteria weights: Level based weight assessment (lbwa) model. Decision Making: Applications in Management and Engineering 2019;. 


\section{Appendix A}

Table A.1: The overall values of traditional type-1 fuzzy set for offshore wind farm site selection criteria.

\begin{tabular}{|c|c|c|c|c|c|}
\hline No & Criteria & Aggregated T1FS & Normalized values & Rank & Degrees \\
\hline $\mathrm{C} 1$ & Wind speed & $(1,0,1)$ & 1.000 & 1 & Critical \\
\hline $\mathrm{C} 2$ & Wind directions & $(0,0,0.84)$ & 0.844 & 35 & Moderate \\
\hline C3 & Wind power density & $(0,0,0.96)$ & 0.958 & 3 & Critical \\
\hline $\mathrm{C} 4$ & Wind resource availability & $(0,0,0.97)$ & 0.966 & 2 & Critical \\
\hline C5 & Effective wind duration (in hours) & $(0,0,0.93)$ & 0.933 & 8 & Critical \\
\hline $\mathrm{C} 6$ & Extreme weather conditions & $(0,0,0.91)$ & 0.906 & 19 & Critical \\
\hline $\mathrm{C} 7$ & Operation lifetime (in years) & $(0,0,0.86)$ & 0.863 & 31 & Moderate \\
\hline $\mathrm{C} 8$ & Total project pay back period & $(0,0,0.92)$ & 0.920 & 13 & Critical \\
\hline $\mathrm{C} 9$ & Expected benefit to cost ratio & $(0,0,0.94)$ & 0.944 & 5 & Critical \\
\hline C10 & Operating revenue & $(0,0,0.92)$ & 0.922 & 12 & Critical \\
\hline C11 & Investment cost & $(0,0,0.94)$ & 0.941 & 6 & Critical \\
\hline C12 & Operation and maintenance costs & $(0,0,0.92)$ & 0.925 & 11 & Critical \\
\hline C13 & Wave energy potential & $(0,0,0.79)$ & 0.791 & 41 & Moderate \\
\hline C14 & Wave height and period & $(0,0,0.82)$ & 0.824 & 39 & Moderate \\
\hline $\mathrm{C} 15$ & Tidal range and current velocity & $(0,0,0.81)$ & 0.813 & 40 & Moderate \\
\hline C16 & Water depth & $(0,0,0.93)$ & 0.926 & 10 & Critical \\
\hline $\mathrm{C} 17$ & Soil conditions & $(0,0,0.87)$ & 0.870 & 29 & Moderate \\
\hline C18 & Being a typhoon and/or earthquake region & $(0,0,0.91)$ & 0.907 & 18 & Critical \\
\hline C19 & Proximity to the shore (Noise, visual impact etc.) & $(0,0,0.94)$ & 0.935 & 7 & Critical \\
\hline $\mathrm{C} 20$ & Proximity to landscape protection area & $(0,0,0.9)$ & 0.896 & 23 & Critical \\
\hline $\mathrm{C} 21$ & Proximity to the facilities for wind farm construction & $(0,0,0.91)$ & 0.912 & 17 & Critical \\
\hline $\mathrm{C} 22$ & Electricity transmission cable installation cost (km/USD million) & $(0,0,0.93)$ & 0.931 & 9 & Critical \\
\hline $\mathrm{C} 23$ & Proximity to grid connections & $(0,0,0.95)$ & 0.950 & 4 & Critical \\
\hline $\mathrm{C} 24$ & Proximity to the electricity demand region & $(0,0,0.89)$ & 0.893 & 24 & Critical \\
\hline $\mathrm{C} 25$ & Proximity to the shipping density/congestion & $(0,0,0.87)$ & 0.870 & 30 & Moderate \\
\hline $\mathrm{C} 26$ & Proximity to shipping lanes & $(0,0,0.87)$ & 0.873 & 28 & Moderate \\
\hline $\mathrm{C} 27$ & Proximity to ports/harbor & $(0,0,0.88)$ & 0.884 & 26 & Critical \\
\hline $\mathrm{C} 28$ & Proximity to navigable waterways & $(0,0,0.86)$ & 0.860 & 32 & Moderate \\
\hline C29 & Proximity to natural environment conservation area & $(0,0,0.9)$ & 0.902 & 20 & Critical \\
\hline $\mathrm{C} 30$ & Effects of wind farm on marine life (marine animals) & $(0,0,0.9)$ & 0.896 & 22 & Critical \\
\hline C31 & Proximity to passage route of birds & $(0,0,0.88)$ & 0.878 & 27 & Moderate \\
\hline C32 & Proximity to contaminated/obstructed area & $(0,0,0.82)$ & 0.824 & 38 & Moderate \\
\hline C33 & Proximity to military operation area & $(0,0,0.86)$ & 0.857 & 33 & Moderate \\
\hline C34 & Proximity to radio and radar corridors (impact on aviation) & $(0,0,0.83)$ & 0.829 & 37 & Moderate \\
\hline C35 & Economic externalities & $(0,0,0.84)$ & 0.843 & 36 & Moderate \\
\hline $\mathrm{C} 36$ & Local economic benefits (employment) & $(0,0,0.86)$ & 0.855 & 34 & Moderate \\
\hline C37 & Proximity to the hydrocarbon reserves & $(0,0,0.77)$ & 0.771 & 42 & Moderate \\
\hline C38 & Investment incentives & $(0,0,0.92)$ & 0.918 & 14 & Critical \\
\hline C39 & Production incentives & $(0,0,0.89)$ & 0.893 & 24 & Critical \\
\hline $\mathrm{C} 40$ & Feed-in-tariff for offshore wind energy & $(0,0,0.9)$ & 0.902 & 21 & Critical \\
\hline $\mathrm{C} 41$ & Community/local acceptance & $(0,0,0.92)$ & 0.916 & 15 & Critical \\
\hline $\mathrm{C} 42$ & Wind farm size (in terms of capacity in MW) & $(0,0,0.91)$ & 0.912 & 16 & Critical \\
\hline
\end{tabular}

